\title{
Microbial production of bi-functional molecules by diversification of the
}

fatty acid pathway

Shivani Garg ${ }^{1,2}$, Ludmila Rizhsky ${ }^{1,3}$, Huanan Jin ${ }^{1,2,4}$, Xiaochen $\mathrm{Yu}^{1,2,4}$, Fuyuan Jing ${ }^{1,2}$, Marna D. Yandeau-Nelson ${ }^{2,5}$, Basil J. Nikolau ${ }^{1,2,4 \S}$

${ }^{1}$ Department of Biochemistry, Biophysics and Molecular Biology, lowa State University, Ames, Iowa, USA

${ }^{2}$ NSF Engineering Research Center for Biorenewable Chemicals, Iowa State University, Ames, Iowa, USA

${ }^{3}$ OmegaChea Biorenewables LLC, Ames, Iowa, USA

${ }^{4}$ Center for Metabolic Biology, lowa State University, Ames, Iowa, USA

${ }^{5}$ Department of Genetics, Development and Cell Biology, lowa State University, Ames, lowa, USA

SG conceived and designed experiments; identified and characterized KASIII enzymes using enzyme activity assays, and thermal shift assays; acquired, interpreted and analysed data, and lead the effort to write the manuscript. LR assembled the E. coli constructs for expressing novel KASIIIs; conducted and interpreted the fatty acid analyses; contributed to writing the manuscript. $\mathrm{HJ}$ constructed the $B$. subtilis and $R$. rubrum strains and analysed fatty acid profiles; contributed to writing the manuscript.

$X Y$ optimized fermentation conditions of $E$. coli strains, and contributed to writing the manuscript.

FJ provided the construct encoding the acyl-ACP thioesterase enzyme used in this study. 
MDY-N oversaw experimental design, data interpretation, and contributed to writing the manuscript.

BJN conceived the scientific idea, participated in experimental design, data interpretation, and revision of the manuscript for important intellectual content. ${ }^{\S}$ Corresponding author

Email addresses:

SG: garg@iastate.edu

LR: ludmilar@iastate.edu

HJ: huananjin@mail.hzau.edu.cn

XY: yux@iastate.edu

FJ: fyjing@iastate.edu

MDY-N: $\underline{\text { myn@iastate.edu }}$

BJN: dimmas@iastate.edu 


\section{ABSTRACT}

Fatty acids that are chemically functionalized at their $\omega$-ends are rare in nature yet offer unique chemical and physical properties with wide ranging industrial applications as feedstocks for bio-based polymers, lubricants and surfactants. Two enzymatic determinants control this w-group functionality, the availability of an appropriate acyl-CoA substrate for initiating fatty acid biosynthesis, and a fatty acid synthase (FAS) variant that can accommodate that substrate in the initial condensation reaction of the process. In Type II FAS, 3-ketoacyl-ACP synthase III (KASIII) catalyses this initial condensation reaction. We characterized KASIIIs from diverse bacterial sources, and identified variants with novel substrate specificities towards atypical acyl-CoA substrates, including 3-hydroxybutyryl-CoA. Using Alicyclobacillus acidocaldarius KASIII, we demonstrate the in vivo diversion of FAS to produce novel $\omega-1$ hydroxy-branched fatty acids from glucose in two bioengineered microbial hosts. This study unveils the biocatalytic potential of KASIII for synthesizing diverse $\omega$-functionalized fatty acids.

\section{KEYWORDS}

3-Ketoacyl-ACP Synthase III; fatty acid synthesis; bio-based chemicals; omega-functionalized fatty acids; substrate diversity; microbial engineering

\section{ABBREVIATIONS}

KASIII: 3-Ketoacyl-ACP-Synthase III

HBFA: $\omega-1$ Hydroxy Branched Fatty Acid

FAS: Fatty Acid Synthase

PHB: Polyhydroxybutyrate 


\section{INTRODUCTION}

The increasing concerns with climate change and price volatility of petroleum feedstocks have prompted a growing search for sustainable sources of chemicals and fuels ${ }^{1,2}$. Fatty acids are chemically the most similar biological molecules to petroleum hydrocarbons, and are therefore the most readily reachable bioengineering targets for developing sustainable replacements of petroleum-derived fuels and chemicals ${ }^{3,4}$. The processes of fatty acid metabolism can generate diverse metabolites with different chemical functionalities, and considerable research efforts have been dedicated to identify the genetic elements, and dissect the enzymology within these metabolic pathways ${ }^{2,5,6}$. Much of this success has been facilitated by the modular nature of the enzymatic machinery that underlies the process of fatty acid synthesis, and the more general process of polyketide biosynthesis ${ }^{7}$. These processes are initiated by the condensation of an acyl-CoA substrate with a 2-carbon donor (malonyl-CoA or malonyl-ACP); and this condensation process is iterated in fatty acid/polyketide biosynthesis cycle to elongate the acyl-chain. Whereas fatty acid synthesis follows each condensation reaction by a 3-reaction process (reduction-dehydration-reduction) that generates a fully reduced alkyl chain, the more general polyketide synthesis mechanism skips one or two of these latter reactions prior to the next condensation iteration, leaving a functional group in the alkyl chain ${ }^{8}$. Examples of such alternative products being generated by fatty acid synthase (FAS) are the

mechanisms by which prokaryotes produce unsaturated fatty acids $^{9}$, and the biosynthesis of methylketones by tomato trichomes ${ }^{10}$. Both these processes intercept the 3-reaction reduction-dehydration-reduction cycle and maintain a 
chemical functional group in the alkyl-chain. The first of these is via an isomerization reaction that moves the carbon-carbon double bond, 1-bond further from the carboxylic acid end of the acyl-chain, ultimately generating an unsaturated fatty acid. In the second example, an acyl-ACP thioesterase that is specific to the 3-ketoacyl-ACP intermediate of FAS intercepts the cycle and releases a 3-ketoacid, which undergoes decarboxylation to generate a methylketone.

We evaluated the feasibility of introducing chemical functional group near the $\omega$-end of fatty acids by exploring the substrate flexibility offered by natural variants of 3-ketoacyl-ACP synthase III (KASIII) ${ }^{11}$, the enzyme that catalyses the initial condensation reaction of Type II FAS systems. Most well characterized KASIII enzymes, including the enzyme from Escherichia coli and most plants, use acetyl-CoA as the substrate in this reaction, and thus the $\omega$-end of the final product is an unreactive methyl-group ${ }^{12}$. However, KASIII from some bacteria, such as Bacillus subtilis and Staphylococcus aureus can utilize substituted acyl-CoAs (i.e., methyl branches at the $\omega-1$ (isobutyryl-CoA) and $\omega-2$ (anteisovaleryl-CoA) positions of the acyl-chain, see supplementary Table 1 for chemical structures of acyl-CoA molecules) ${ }^{12,13}$. These organisms therefore produce fatty acids with methyl branches at or near the $\omega$-ends of the molecules. Therefore, we projected that by providing chemically substituted acyl-CoA substrates to novel KASIII enzymes, one can envision biosynthesizing $\omega$-functionalized fatty acids. Moreover, KASIII are archetypal for many Type III polyketide synthases which catalyse similar Claisen condensation reactions between an acyl-CoA and a malonyl-CoA/ACP 
thioester substrate ${ }^{14}$ and also show great flexibility in being able to use a variety of acyl-CoA substrates, generating a large collection of polyketide specialized metabolites.

In this study, we specifically tested this hypothesis and demonstrated the ability to biologically produce $\omega-1$ Hydroxy Branched Fatty Acids (HBFAs) using the novel KASIII enzyme from Alicyclobacillus acidocaldarius coupled with a system to generate 3-hydroxyacyl-CoA as a substrate for this novel KASIII enzyme. The utility of such bi-functional hydroxy acids is in such applications as polymers (e.g., polyesters) and specialized natural surfactants (e.g., sophorolipids) ${ }^{15}$. The system that we have developed has more general applications in that it illustrates the flexibility of Type II FAS systems. These systems can be bioengineered to accept novel initiating acyl-CoA substrates by exploiting the variant enzymes that catalyse the initial condensation reaction and define the $\omega$-end of the final product (i.e., KASIII). A cursory examination of sequence databases ${ }^{16}$ currently identifies 14,000 potential KASIII enzymes that could be used to generate a variety of different bifunctional molecules ${ }^{17}$.

\section{RESULTS}

\section{Computational identification of KASIIIs from diverse bacterial sources}

Putative KASIII-coding genes were computationally identified by sequence homology, by searching genomic sequences from diverse bacteria that are known to produce large amounts of either terminally branched chain fatty acids or $\omega$-cyclic fatty acids. We projected that organisms that produce large quantities of branched chain or $\omega$-cyclic fatty acids should express novel 
KASIII enzymes that are capable of utilizing branched-chain acyl-CoAs or $\omega$ cyclic acyl-CoAs as substrates to initiate fatty acid biosynthesis. We further hypothesized that such KASIII enzymes will have relatively larger substrate binding pockets that can not only accommodate branched or $\omega$-cyclic acylCoA substrates, but could also accommodate other bulky substrates, such as aromatic, hydroxylated or unsaturated acyl-CoAs.

Based on these presuppositions, we characterized two KASIII enzymes, one from the thermophile Thermus aquaticus, an organism that can produce $95 \%$ branched chain fatty acids ${ }^{18}$ and another from the acidothermophile $A$. acidocaldarius, which can produce large proportion of $\omega$-alicyclic fatty acids (59\%) and branched chain fatty acids $(36 \%)^{19}$. We compared the properties of the $A$. acidocaldarius (aaKASIII) and T. aquaticus (taKASIII) enzymes to two functionally well-characterized KASIIIs, one from E. coli (ecKASIII, encoded by $f a b H$ gene), and the second from $B$. subtilis (bsKASIIlb, encoded by the yhfB gene). These latter two enzymes were selected because they are known to display different substrate specificity; ecKASIII is specific for acetyl-CoA and is unable to use branched chain acyl-CoA substrates ${ }^{12,20}$, whereas bsKASIIIb can utilize both acetyl-CoA and branched-chain acyl-CoA substrates $^{12}$.

Primary sequence analyses of aaKASIII and taKASIII revealed that each possesses the conserved catalytic triad residues (Cys, His and Asn; Supplementary Fig. 1) typical of KASIII enzymes, suggesting that both belong to the family of decarboxylating thiolase enzymes ${ }^{14}$. Moreover, both aaKASIII 
and taKASIII contain the substrate binding residues that are conserved among well-characterized KASIII enzymes ${ }^{13}$ (see Supplementary Fig.1).

\section{In vivo analysis of KASIII function in a $B$. subtilis $\Delta y j a X \Delta y h f B$ strain}

The bacterium $B$. subtilis primarily synthesizes branched chain fatty acids $(95 \%)^{21}$, and possesses two KASIII homologs, bsKASIIla (encoded by the yjaX gene) and bsKASIIlb (encoded by the yhfB gene); both possess high specificity for branched chain acyl-CoA substrates ${ }^{12}$. Deletion of these two endogenous KASIII genes from $B$. subtilis results in a lethal phenotype, which can be rescued by growing the double mutant strain in the presence of branched-chain fatty acids (Jin and Nikolau, unpublished data). This $B$. subtilis $\Delta y j a X \Delta y h f B$ mutant strain was used as a vehicle to screen for KASIII enzymes that can utilize branched chain acyl-CoA substrates and can therefore synthesize branched chain fatty acids, thereby rescuing the lethal condition. The selected aaKASIII and taKASIII were assessed for their ability to support the production of branched chain fatty acids, by integrating each of them into the genome of the $B$. subtilis $\Delta y j a X \Delta y h f B$ mutant strain. In parallel, the ecKASIII that is unable to utilize branched-chain substrates ${ }^{12}$ was also integrated into the genome of this strain. The resulting three B. subtilis $\Delta y j a X$ $\Delta y h f B$ mutant strains, each expressing one of the recombinant KASIII genes, were grown in the presence and absence of exogenously supplied branchedchain fatty acids. Of the three recombinant KASIII genes that were tested, aaKASIII and taKASIII could rescue the lethal phenotype of the $\Delta y j a X \Delta y h f B$ mutant strain but as expected the ecKASIII could not, and this strain could not grow in media that does not contain branched-chain fatty acids. 
Fatty acid analysis of the $B$. subtilis $\Delta y j a X \Delta y h f B$ strains harbouring either aaKASIII or taKASIII revealed that both strains could produce similar branched chain fatty acid profiles, with anteiso-branched chain fatty acids accounting for the largest portion of the fatty acids (48-52\%), followed by iso-

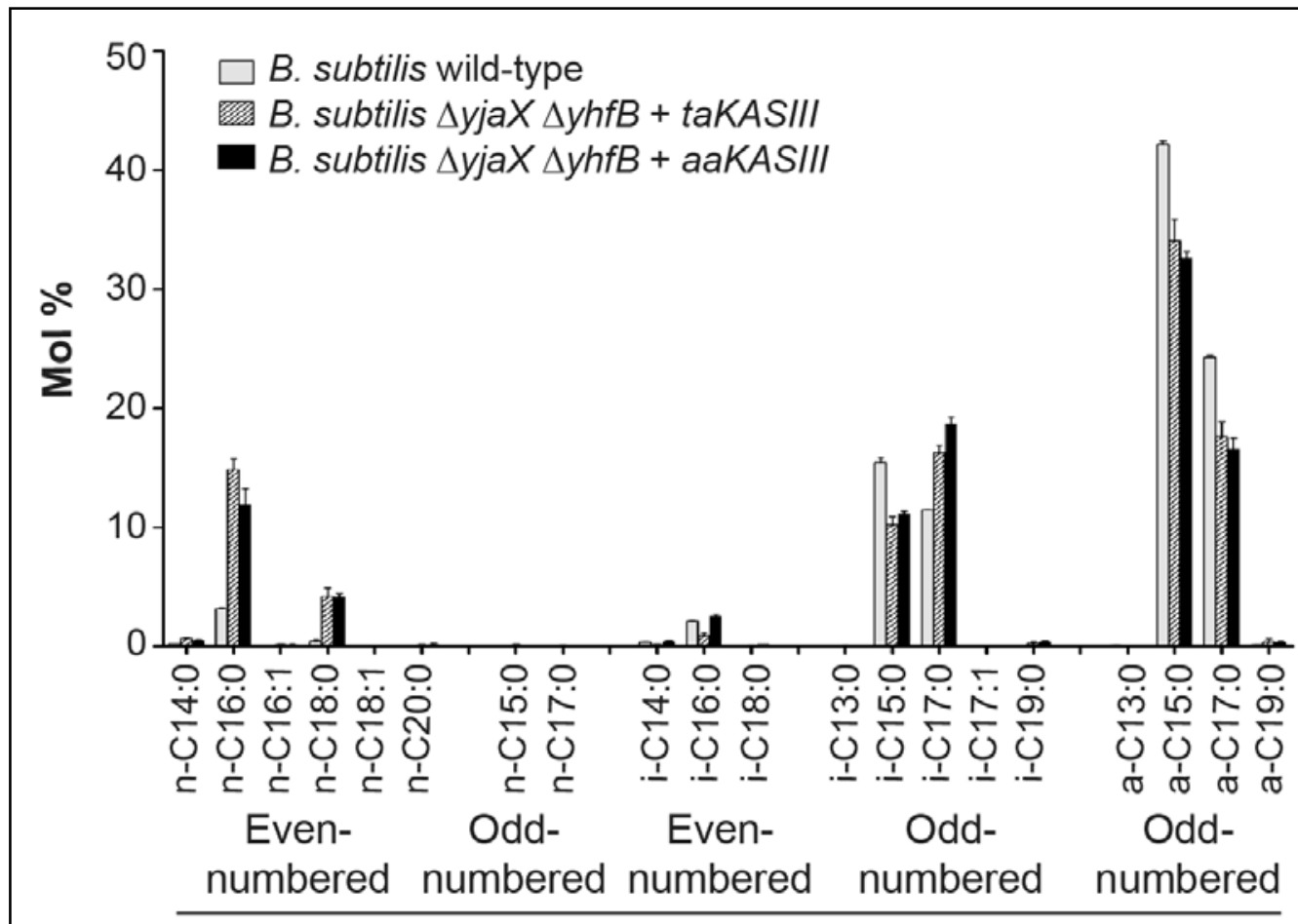

Fatty acids

Figure 1 | Effect of expressing exogenous KASIII genes on the fatty acid profiles of $B$. subtilis. The fatty acid profile of the $B$. subtilis wild-type strain is compared to that of the $B$. subtilis $\triangle y j a X \triangle y h f B$ deletion mutant strain expressing either taKASIII (from $T$. aquaticus) or aaKASIII (from $A$. acidocaldarius). The double mutant strain cannot grow in the absence of the ectopically expressed KASIII genes. Each data point is an average of 3 experiments, and error bars represent standard deviations. n-Cn:x represent normal (straight chain) fatty acids, i-Cn:x represent iso-branched chain fatty acids and a-Cn:x represent anteiso-branched chain fatty acids, where $\mathrm{n}=$ number of carbon atoms, and $\mathrm{x}=$ number of carbon-carbon double bonds in the acyl-chain. 
branched chain fatty acids (27-34\%) (Fig. 1). These data establish that aaKASIII and taKASIII have the ability to use both anteiso-branched and isobranched acyl-CoA substrates for priming fatty acid biosynthesis.

In vitro analysis of KASIII function, and identification of KASIII enzymes with atypical substrate preferences

We used pure enzyme systems to directly evaluate whether the active sites of aaKASIII and taKASIII could accommodate branched chain acyl-CoAs and even bulkier and more polar acyl-CoA substrates, such as hydroxylated, aromatic or diacidic acyl-CoAs (see supplementary Table 1 for chemical structures of acyl-CoAs). These in vitro characterizations compared the properties of the aaKASIII and taKASIII enzymes with those obtained in parallel with ecKASIII and bsKASIIIb.

Each recombinantly expressed KASIII enzyme was purified to nearhomogeneity (Supplementary Fig. 2), and we initially confirmed that they each showed an appropriately folded structure by Circular Dichroism (CD) spectroscopy (Supplementary Fig. 3). All of four KASIII proteins showed similar CD spectra that indicated they are folded.

Each recombinant KASIII protein was then evaluated for its ability to bind potential acyl-CoA substrates using a fluorescence-based thermal shift assay $^{22-24}$, which measures the thermal stability of a protein in the presence or absence of a specific ligand. A positive shift in melting temperature $\left(T_{m}\right)$ of the protein in the presence of the ligand is correlated to binding, concomitant with 
the stabilization of the protein, which is consistent with the substrate-induced contraction of protein structures that are often observed with enzymes. In contrast, a negative shift in $T_{m}$ suggests destabilization of the protein by the ligand.

Each KASIII was assayed with ligands that are typical substrates of wellcharacterized KASIII enzymes, including straight, short-chain acyl-CoAs (e.g., acetyl-CoA, propionyl-CoA, butyryl-CoA, hexanoyl-CoA) and branched chain acyl-CoAs (e.g., isobutyryl-CoA, isovaleryl-CoA). In addition, we also used acyl-CoAs that are atypical of known KASIII substrates, such as diacidic (malonyl-CoA, methylmalonyl-CoA), hydroxylated (3-hydroxybutyryl-CoA), unsaturated (crotonyl-CoA), and aromatic (benzoyl-CoA and phenylacetylCoA) acyl-CoAs (see supplementary Table 1 for chemical structures of acylCoAs).

The inherent $T_{m} S$ of the four KASIII enzymes in the absence of ligand are shown in Figure $2 \mathrm{a}$, and these values were used as the baseline to measure the shift in $T_{m}$ by addition of the potential substrate ligands. The higher $T_{m} s$ of the aaKASIII and taKASIII are consistent with their origin from thermophilic bacteria. When the thermal shift assays were conducted in the presence of potential substrate ligands, the KASIIIs from $B$. subtilis, $A$. acidocaldarius and T. aquaticus demonstrated positive changes in $T_{m}$ with a broad range of acylCoAs. In contrast, such a positive change in $T_{m}$ for ecKASIII was obtained only with acetyl-CoA (Fig. 2b), which is consistent with the narrow substrate specificity of this enzyme ${ }^{12}$. 


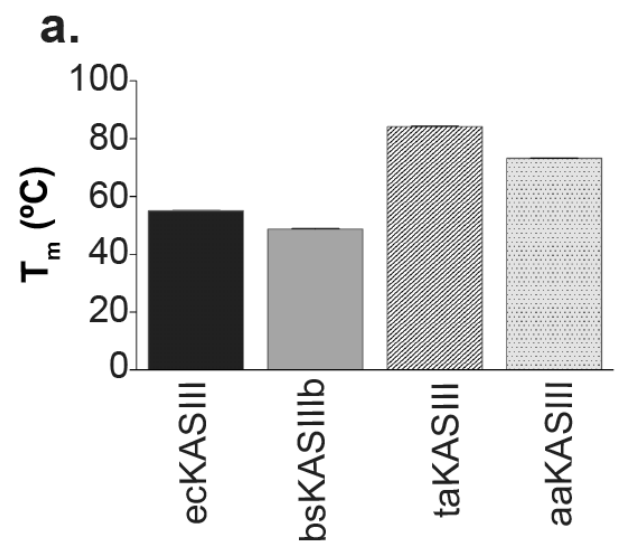

b.

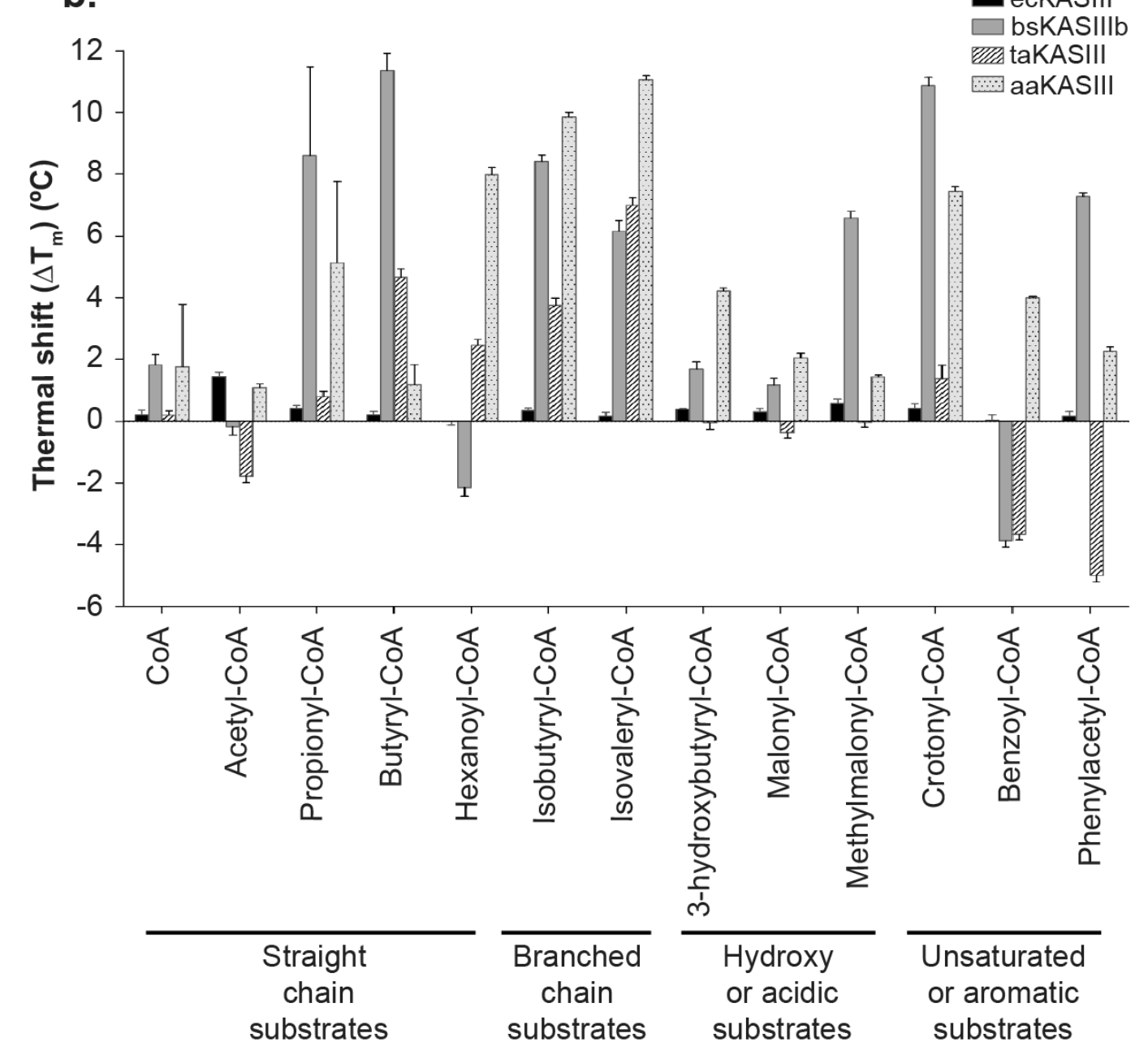

Figure 2 | Effect of different acyl-CoAs on the thermal stability of different KASIIIs. a) The melting temperature $\left(T_{m}\right)$ of each KASIII enzyme in the absence of any ligands. b) Change in the melting temperatures $\left(\Delta T_{m}\right)$ of the selected KASIIIs upon addition of different acyl-CoA ligands. Each data point represents the average of four technical replicates, and the error bars represent standard deviations. 
The bsKASIIIb and aaKASIII enzymes exhibited significant increases in $T_{m}$ (4$\left.6{ }^{\circ} \mathrm{C}\right)$ when incubated with many different acyl-CoA ligands, including those with straight, branched, diacidic, unsaturated or aromatic acyl-chains (Fig. 2b). Specifically, aaKASIII exhibited significant positive shifts in $T_{m}$ when incubated with bulky or unsaturated ligands, including 3-hydroxybutyryl-CoA, crotonyl-CoA and benzoyl-CoA. Similarly, bsKASIIlb exhibited positive shifts in $T_{m}$ in the presence of 3-hydroxybutyryl-CoA, methylmalonyl-CoA, crotonylCoA and phenylacetyl-CoA $\left(10^{\circ} \mathrm{C}\right.$ shift). However, some of the atypical acylCoAs (i.e., hexanoyl-CoA and benzoyl-CoA) destabilized the bsKASIIlb protein (i.e., decreased the $T_{m}$ ).

\section{A unique KASIII that utilizes 3-hydroxybutyryl-CoA as a substrate}

We focused further studies on identifying a KASIII that is most likely capable of using 3-hydroxybutyryl-CoA as a substrate in order to use such an enzyme to produce hydroxy-fatty acids. The thermal shift assays indicated that of the four KASIII enzymes tested, aaKASIII and bsKASIIIb were both thermally stabilized by 3-hydroxybutyryl-CoA, and that this stabilization was largest for the aaKASIII enzyme. This finding suggested that aaKASIII might utilize 3hydroxybutyryl-CoA as a substrate. Using an in vitro spectrophotometric enzyme assay (see Methods), we tested the ability of aaKASIII to utilize 3hydroxybutyryl-CoA and malonyl-ACP as substrates and produce 5-hydroxy3-ketohexanoyl-ACP. The specific activity for this reaction catalysed by aaKASIII is 5-fold and 3-fold higher with isobutyryl-CoA and 3-hydroxybutyrylCoA, respectively, than that obtained with acetyl-CoA (Table 1). Kinetic characterization of aaKASIII revealed that isobutyryl-CoA is the preferred 
substrate compared to acetyl-CoA and 3-hydroxybutyryl-CoA (Table 1). The order of catalytic efficiency (i.e. $\mathrm{k}_{\mathrm{cat}} / \mathrm{K}_{\mathrm{m}}$ ) of aaKASIII with various substrates was: isobutyryl-CoA > 3-hydroxybutyryl-CoA > acetyl-CoA (Table 1).

\section{Table 1. Steady state kinetic analysis of aaKASIII and comparison with ecKASIII}

KASIII enzyme assay was carried out spectrophotometrically using $400 \mu \mathrm{M}$ ACP , $400 \mu \mathrm{M}$ malonyl-CoA, 10-400 $\mu \mathrm{M}$ various acyl-CoAs, $400 \mu \mathrm{M}$ NADPH,

$1 \mathrm{mM}$ DTT, $60 \mu \mathrm{g}$ FabD, $30 \mu \mathrm{g}$ FabG and $4 \mu \mathrm{g}$ of aaKASIII (or $9.5 \mu \mathrm{g}$ of ecKASIII).

\begin{tabular}{|c|c|c|c|c|c|c|}
\hline Enzyme & Substrate & $\mathbf{K}_{\mathrm{m}}(\mu \mathrm{M})$ & $\begin{array}{c}\mathbf{V}_{\max } \\
(\mu \mathrm{moles} / \mathrm{s})\end{array}$ & $\mathbf{k}_{\text {cat }}\left(\mathrm{s}^{-1}\right)$ & $\begin{array}{c}\text { Specificity } \\
\text { constant } \\
\mathbf{k}_{\text {cat }} / K_{\mathbf{m}^{-1}}\left(\mu \mathrm{M}^{-}\right. \\
\left.{ }^{-1}\right)\end{array}$ & $\begin{array}{c}\text { Specific } \\
\text { activity } \\
(\mathrm{nmol} / \mathrm{mg} / \mathrm{mi} \\
\mathrm{n})\end{array}$ \\
\hline \multirow{3}{*}{$\begin{array}{c}A . \\
\text { acidocaldarius } \\
\text { KASIII }\end{array}$} & Acetyl-CoA & $114.6 \pm 14.5$ & $\begin{array}{r}1.6 \mathrm{E}-04 \pm \\
0.2 \mathrm{E}-04\end{array}$ & $\begin{array}{r}25.2 \mathrm{E}-03 \pm \\
4.42 \mathrm{E}-03\end{array}$ & $\begin{array}{r}21.8 \mathrm{E}-05 \pm \\
1.0 \mathrm{E}-05\end{array}$ & $10.3 \pm 2.6$ \\
\hline & Isobutyryl-CoA & $59.4 \pm 13.6$ & $\begin{array}{r}10.2 \mathrm{E}-04 \pm \\
2.9 \mathrm{E}-04\end{array}$ & $\begin{array}{r}154.3 \mathrm{E}-03 \pm \\
45.3 \mathrm{E}-03\end{array}$ & $\begin{array}{r}255.6 \mathrm{E}-05 \pm \\
17 \mathrm{E}-05\end{array}$ & $56.0 \pm 6.3$ \\
\hline & $\begin{array}{l}\text { 3-Hydroxybutyryl- } \\
\text { CoA }\end{array}$ & $249.7 \pm 2.5$ & $\begin{array}{r}7.2 \mathrm{E}-04 \pm \\
0.8 \mathrm{E}-04\end{array}$ & $\begin{array}{r}109.8 \mathrm{E}-03 \pm \\
13.6 \mathrm{E}-03\end{array}$ & $\begin{array}{r}44 \mathrm{E}-05 \pm 5.9 \mathrm{E}- \\
05\end{array}$ & $33.4 \pm 1.1$ \\
\hline \multirow[t]{3}{*}{ E. coli KASIII } & Acetyl-CoA & $96.8 \pm 4.7$ & $\begin{array}{r}3.3 \mathrm{E}-04 \pm \\
0.1 \mathrm{E}-04\end{array}$ & $\begin{array}{r}21.4 \mathrm{E}-03 \pm \\
0.93 \mathrm{E}-03\end{array}$ & $\begin{array}{r}22.1 \mathrm{E}-05 \pm \\
1.1 \mathrm{E}-06\end{array}$ & $447 \pm 68$ \\
\hline & Isobutyryl-CoA & Not a substrate & & & & \\
\hline & $\begin{array}{l}\text { 3-Hydroxybutyryl- } \\
\text { CoA }\end{array}$ & Not a substrate & & & & \\
\hline
\end{tabular}

\section{Production of HBFAs by expressing aaKASIII in Rhodospirillum rubrum}

Having identified that aaKASIII can utilize 3-hydroxybutyryl-CoA as a substrate, we expressed this enzyme in the purple phototrophic bacterium Rhodospirillum rubrum with the specific aim of producing HBFAs via the fatty acid synthesis pathway. R. rubrum was chosen for these experiments because this organism produces large quantities of the biopolymer polyhydroxybutyrate (PHB) (over $50 \%$ of dry biomass of the cells ${ }^{25}$ ), and therefore must have the capacity to produce large quantities of the precursor, 3-hydroxybutyryl-CoA. The 3-hydroxybutyryl-CoA intermediate is synthesized via PhaA-catalyzed condensation of two acetyl-CoA molecules to yield acetoacetyl-CoA, which is then reduced by PhaB to yield 3-hydroxybutyrylCoA. In the native host, 3-hydroxybutyryl-CoA is polymerized by PhaC to 


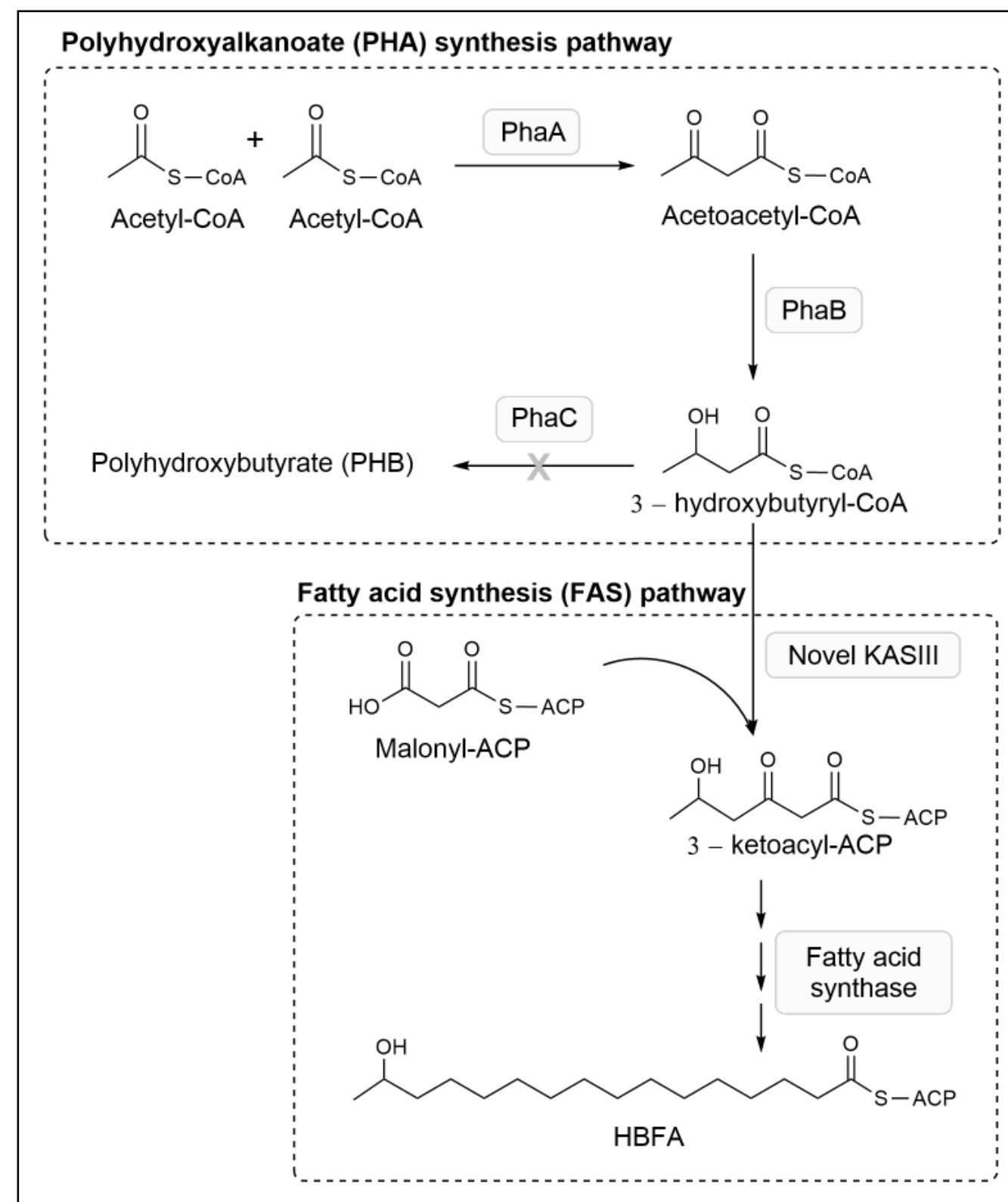

Figure 3 | Schematic representation of the bioengineered pathway for production of HBFA. Polyhydroxybutyrate (PHB) is synthesized from acetyl-CoA via the sequential action of the enzymes 3-ketothiolase (PhaA), acetoacetyl-CoA reductase (PhaB) and PHB polymerase (PhaC). The carbon-flow was diverted towards the biosynthesis of HBFAs via fatty acid synthase by ectopically expressing a novel KASIII variant from $A$. acidocaldarius in a $R$. rubrum strain that lacks any PhaC activity.

assemble PHB (Fig. 3). The R. rubrum genome encodes three PhaCencoding genes (phaC1, phaC2, and phaC3), and a triple phaC mutant strain ( $\triangle p h a C 1 \Delta p h a C 2 \Delta p h a C 3$ ) is incapable of accumulating PHB, but suffers only a slight growth-penalty ${ }^{26}$. We reasoned therefore that this triple mutant strain 
has the capacity to generate 3-hydroxybutyryl-CoA, which could serve as a substrate for aaKASIII to produce HBFAs (Fig. 3). We tested this hypothesis by recombinantly expressing the aaKASIII in the R. rubrum $\triangle$ phaC1 $\triangle$ phaC2 $\triangle p h a C 3$ strain that lacks any functional phaC enzymes, and then analysed the resultant fatty acids by GC-MS.

These analyses detected a novel product in the aaKASIII-expressing strain corresponding to the silylated-derivative of the methyl-ester of 15hydroxyhexadec-9-enoic acid, which was not produced by the control strain that did not express the recombinant aaKASIII (Fig. 4a, 4b). These results therefore confirm the aaKASIII-dependent production of a monounsaturated HBFA in the $R$. rubrum triple mutant host. This novel bi-functional fatty acid accounted for $0.19 \pm 0.04 \mathrm{~mol} \%$ of the fatty acids produced by the $R$. rubrum strain (Fig. 4c). Additionally, novel iso- and anteiso-branched chain fatty acids of varying carbon chain lengths that do not occur in the control strain were produced in the aaKASIII-expressing strain, and these accounted for approximately $1.3 \mathrm{~mol} \%$ of the fatty acids (Fig. 4c). Taken together, our data establish that the aaKASIII is able to utilize hydroxyacyl-CoA (i.e., 3hydroxybutyryl-CoA) (Fig. 3) or branched chain acyl-CoAs (i.e., iso- and anteiso-acyl-CoAs) in vivo, resulting in the respective formation of HBFAs or iso/anteiso branched chain fatty acids that are not naturally produced by the host bacterium. 


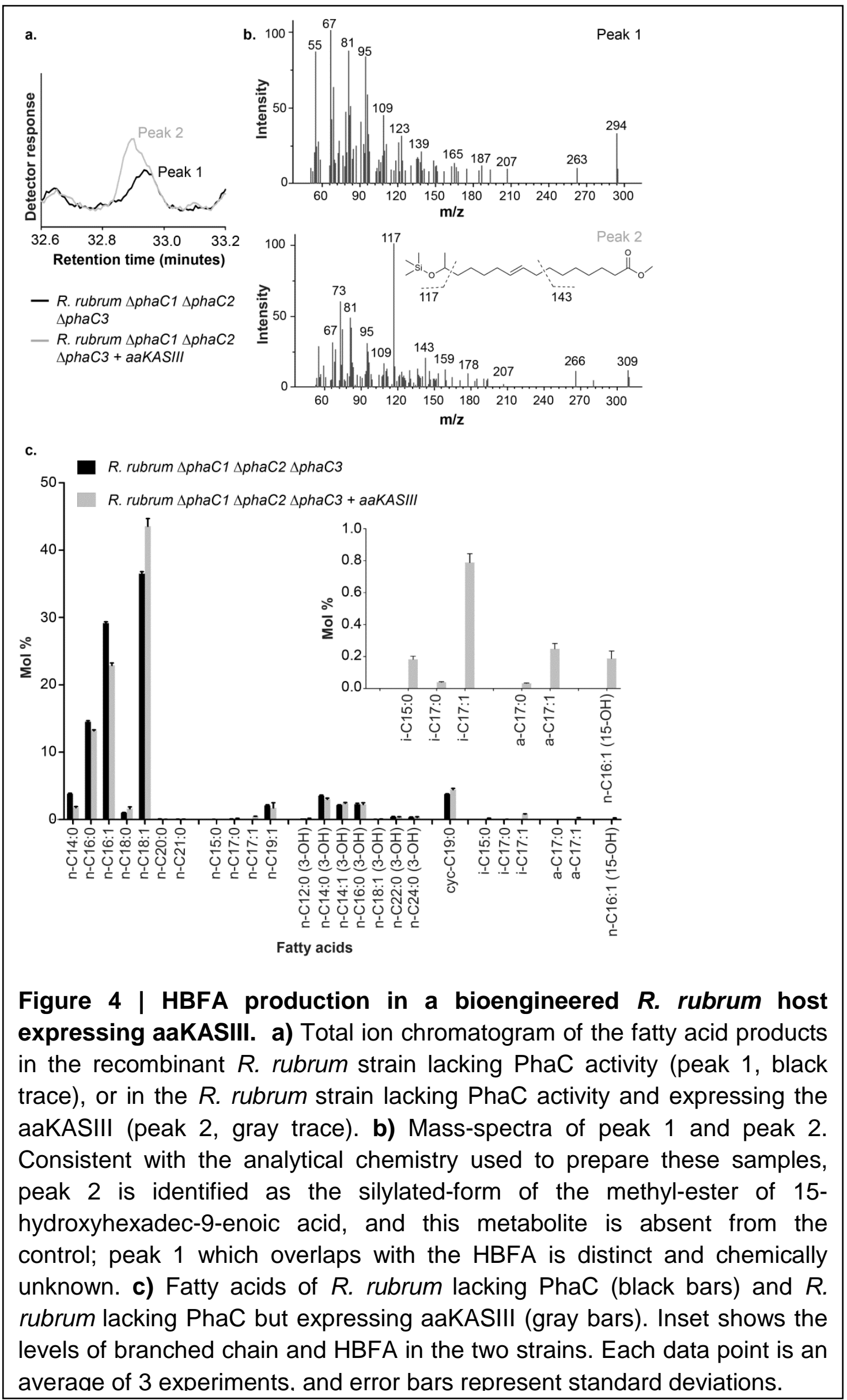


Optimizing the production of HBFA by expressing aaKASIII in a bioengineered $\boldsymbol{E}$. coli host. Having demonstrated the production of bifunctional fatty acids in $R$. rubrum, we attempted production of HBFAs in a bioengineered $E$. coli host. We reasoned that use of $E$. coli would open avenues to applying a wide range of molecular genetic tools to improve the titer of these novel fatty acids. Specifically, we co-expressed in E. coli the aaKASIII, with the $R$. rubrum phaA and phaB genes, thus recapitulating the initiating part of the pathway that should lead to the biosynthesis of HBFAs (Fig. 3). The E. coli strain (OC100) that we used for this experiment carried deletion mutations of the ecKASIII encoded by fabH $\left(\Delta \mathrm{fabH}:: \mathrm{kam}^{R}\right)$ gene and of the fadD $\left(\Delta f a d D:: c^{R} m^{R}\right)$ gene. The rationale for incorporating these genedisruptions in an E. coli production host are to 1) ensure minimal interference by the native KASIII, and 2) eliminate $\beta$-oxidation of fatty acids to facilitate the accumulation and secretion of the novel fatty acid products into the medium. We generated the bioengineered $E$. coli strain (OC101) by overexpressing aaKASIII, the $R$. rubrum phaA and phaB genes in OC100 strain.

After 12 hours of growth, fatty acids were extracted from the spent media used to grow strain OC101, and these were analysed by GC-MS. Figure 5a shows the presence of novel peaks corresponding to HBFAs of 14-, 16- and 18-carbon chain lengths, either without any carbon-carbon double bonds, or with one double bond at the $\omega-7$ position of the molecules (Fig. 5a). These peaks were absent in the control E. coli strain OC100 that carried the $\Delta \mathrm{fabH}$ and $\triangle f a d D$ mutations, but did not carry the phaA, phaB and aaKASIII genes. Quantitative analysis shows that the titer of HBFA was approximately $1 \mathrm{mg} / \mathrm{L}$, 
which constituted $43 \%$ of the fatty acids in the media (Fig. 5b). 15Hydroxyhexadec-9-enoic acid was the most abundant HBFA, followed by 15hydroxyhexadecanoic acid (see Supplementary Fig. 4 and 5 for MS-spectral confirmation data). In summary, recapitulating the pathway for HBFA production in $E$. coli has provided a genetically tractable platform for optimizing productivity, and prior to genetic optimization it is a platform that expresses at a titer at least 1000-fold higher than that achieved in R. rubrum.

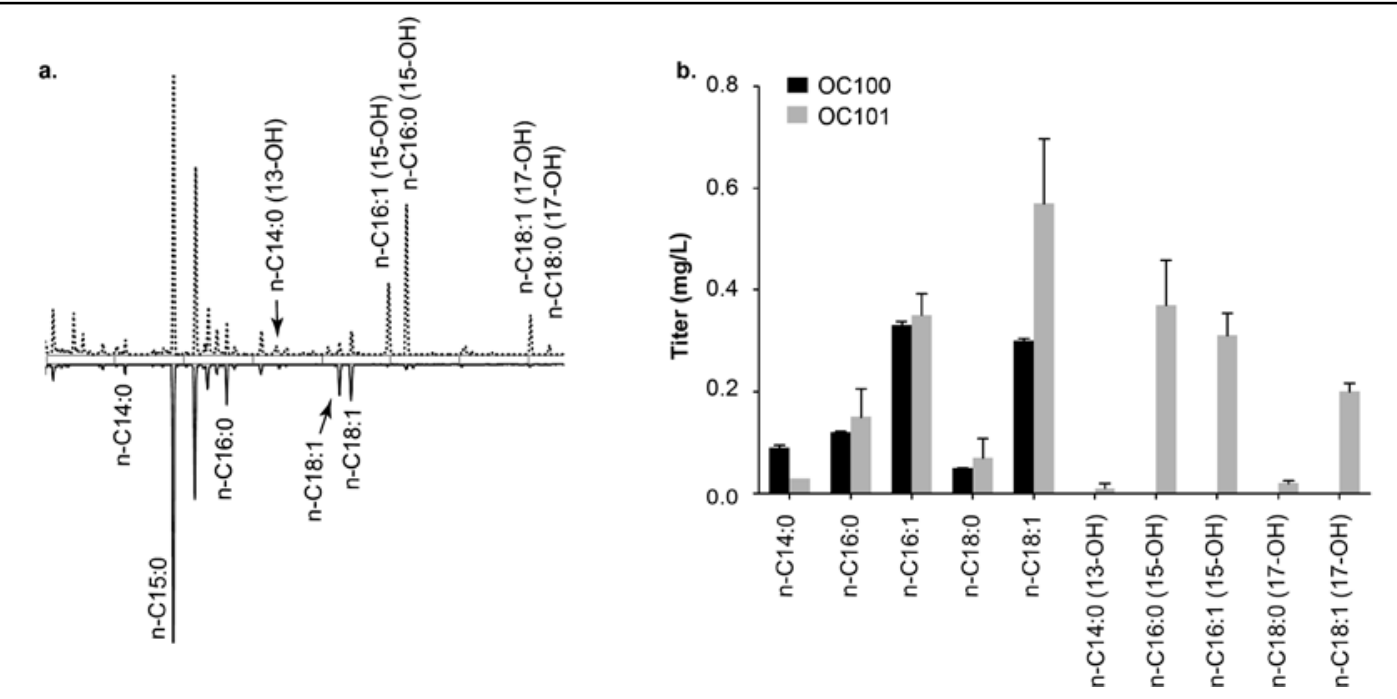

Figure 5 | HBFA production in a bioengineered $E$. coli host. a) Extracted ion chromatogram (based on $\mathrm{m} / \mathrm{z}$ ion $117^{+}$) of the fatty acid products recovered from the recombinant $E$. coli $\triangle f a b H \triangle f a d D$ (strain OC100; lower panel, black trace), and from the E. coli $\triangle \mathrm{fabH} \Delta \mathrm{fadD}$ strain co-expressing phaA, phaB and aaKASIII genes (strain OC101; upper panel, dotted trace). Mass-spectra of the identified HBFAs are shown in Supplementary Figures 4 and 5. b) Extracellular fatty acid profiles of $E$. coli $\triangle \mathrm{fabH} \triangle \mathrm{fadD}$ (strain OC100; black bars) and E. coli $\triangle \mathrm{fabH} \triangle \mathrm{fadD}$ strain co-expressing phaA, phaB and aaKASIII genes (strain OC101; gray bars). Each data point is an average of 3 experiments, and error bars represent standard deviations.

We attempted to increase the HBFA production levels by overexpressing an acyl-ACP thioesterase (TE) isolated from a plant source (Cuphea seeds), which prior studies indicated could affect a higher titer of fatty acids when 
expressed in $E$. coli ${ }^{27}$. Upon overexpressing this TE in strain OC101, the titers of fatty acids and HBFAs did not increase, but in fact were reduced to $20 \%$ of the levels that was produced by the OC101 strain.

\section{Optimizing HBFA titer via manipulation of fermentation conditions}

A standardized culturing system was implemented to explore the effect of different fermentation conditions on the ability of strain OC101 to produce HBFA. Unless otherwise stated, this consisted of $125 \mathrm{ml}$ flasks with a working volume of $25 \mathrm{ml}$ media maintained at $37{ }^{\circ} \mathrm{C}$ and agitated at $250 \mathrm{rpm}$, and induced with IPTG. In these non-optimized fermentation conditions in LB media, E. coli strain OC101 produced $4.6 \mathrm{mg} / \mathrm{L}$ of HBFA upon reaching stationary phase, which accounted for about $40 \%$ of the fatty acids secreted into the medium. To optimize the fermentation conditions, the carbon to nitrogen ratio $(\mathrm{C} / \mathrm{N})$ in the initial culture medium and size of the inoculum in establishing the culture were varied. The $\mathrm{C} / \mathrm{N}$ ratio $^{28,29}$ and inoculum size 30,31 have been demonstrated to have significant effects on cell growth and fatty acid production by different microorganisms (supplementary Table 4). Additionally, induction temperature, induction time and concentration of the inducer, i.e., IPTG, were also varied as these are also known to be factors influencing the expression of a transgenic protein, thus may significantly affect the final fatty acid titer ${ }^{32,33}$ (supplementary Table 4).

Figure 6 shows the impact of altering the five fermentation parameters described above on the HBFA and fatty acid titers when strain OC101 is cultured in M9 minimal media. HBFA and fatty acid titers increased with 
increasing $\mathrm{C} / \mathrm{N}$-ratio (Fig. 6a), with the most dramatic increase occurring as the ratio was increased from 25 to 50 . The highest HBFA titer occurred at a $\mathrm{C} / \mathrm{N}$ ratio of 75 , with the HBFA titer reaching $7.2 \mathrm{mg} / \mathrm{L}$. Based upon these results, in the following experiments ammonium chloride was supplemented in the media at $0.41 \mathrm{~g} / \mathrm{L}$, to achieve a C/N-ratio of 75 .

Altering the size of the inoculum from $1 \%(\mathrm{v} / \mathrm{v})$ to $10 \%(\mathrm{v} / \mathrm{v})$ resulted in increased cell growth (Supplementary Fig. 6a) and enhanced extracellular fatty acid titers (Fig. 6b). Optimal fatty acid and HBFA titers (10.1 mg/L and $9.0 \mathrm{mg} / \mathrm{L}$ at, respectively) occurred at an inoculum size of $7 \%(\mathrm{v} / \mathrm{v})$.

The post-induction temperature of the culture had considerable impact on both cellular growth (Supplementary Fig. 7a) and extracellular fatty acid production (Fig. 6c). When post-induction temperature was maintained at 30 ${ }^{\circ} \mathrm{C}$ or $37{ }^{\circ} \mathrm{C}$, the culture reached stationary phase by about $15 \mathrm{~h}$ postinduction and achieved final ODs of 2.4 at $30{ }^{\circ} \mathrm{C}$ and 1.5 at $37^{\circ} \mathrm{C}$. However, at the lower temperature $\left(25^{\circ} \mathrm{C}\right)$, the culture maintained logarithmic growth for about $28 \mathrm{~h}$, reaching a final OD of 4.6. The highest extracellular fatty acid and HBFA titers of $14.5 \mathrm{mg} / \mathrm{L}$ and $10.8 \mathrm{mg} / \mathrm{L}$, respectively, were achieved at 30 ${ }^{\circ} \mathrm{C}$. Moreover, the post-induction temperature of the culture posed a significant effect on the proportion of HBFAs secreted by the strain (Supplementary Fig. $7 \mathrm{~b}$ ); at $20^{\circ} \mathrm{C}$ or $25{ }^{\circ} \mathrm{C}$, HBFAs accounted between $75 \%$ $80 \%$ of the extracellular fatty acids, whereas at $30{ }^{\circ} \mathrm{C}$ and $37{ }^{\circ} \mathrm{C}$, they accounted for $85 \%$ and $62 \%$ of the fatty acids, respectively, which may be attributable to the poorer cell growth at the higher temperatures. 


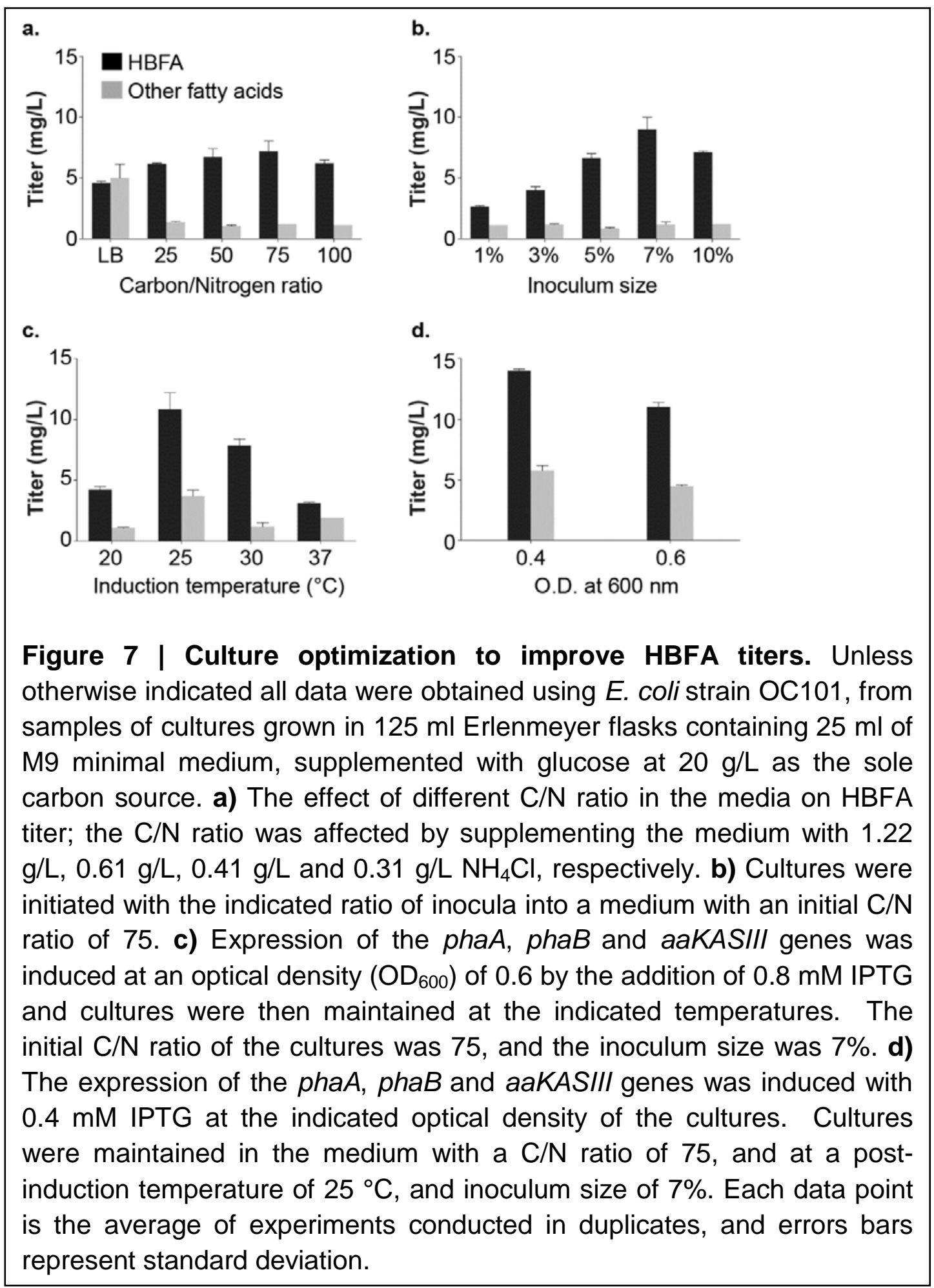

Finally, we also assessed the effect of inducing the culture at different stages of growth or with different concentrations of the inducer, IPTG (Fig. 6d and Supplementary Fig. 8a, 8b). Generally, the highest titers of both fatty acids 
and HBFAs (13-14 mg/L) were obtained when $0.4 \mathrm{mM}$ IPTG was introduced into the culture at an OD of 0.4 .

In these optimization experiments, the dominant fatty acids were C16:1-, C16:0- and C18:1-HBFAs (Supplementary Fig. 6b, 7b). Overall these optimization experiments of $E$. coli strain OC101 increased titers of fatty acids and HBFAs by 3-fold from those obtained in the non-optimized culture conditions, reaching values of $25.1 \mathrm{mg} / \mathrm{L}$ and $13.8 \mathrm{mg} / \mathrm{L}$, respectively. These optimum conditions in M9 minimal media occur at a carbon-to-nitrogen ratio of 75 , inoculum size of $7 \%(\mathrm{v} / \mathrm{v})$, post-induction temperature of $25^{\circ} \mathrm{C}$ and with $0.4 \mathrm{mM}$ IPTG added when the culture was at early log-phase at an OD 0.4 (Supplementary Fig. 9).

\section{DISCUSSION}

In this study, we demonstrated the production of HBFAs from glucose, first by eliminating the ability of $R$. rubrum to produce $\mathrm{PHB}$, and diverting its precursor (i.e., 3-hydroxyacyl-CoA) into fatty acid biosynthesis with a KASIII variant that shows novel substrate specificity, aaKASIII. Subsequently, we recapitulated this metabolic pathway in a bioengineered $E$. coli host. The resultant strain produced HBFAs of 14-18 carbon-chain lengths, with or without carboncarbon double bonds. Additional optimization by altering the fermentation conditions increased the titer of this valuable product to $13 \mathrm{mg} / \mathrm{L}$, which was over 1000-fold greater than the titer obtained in the initial $R$. rubrum demonstration host. In this study, we made the assumption that HBFAs are recovered in the growth medium, based on many other studies that use fadD 
mutation and report secretion of fatty acids in the medium ${ }^{34,35}$. However, cell lysis at stationary phase may still be the means of getting HBFAs in the growth medium.

Metabolically intercepting Type II FAS via these genetic engineering manipulations required the identification and characterization of bacterial KASIII enzyme variants isolated from $B$. subtilis, T. aquaticus and $A$. acidocaldarius, and their properties were compared to the E. coli sourced enzyme. The bsKASIIlb was known to have the property of using larger acylCoA substrates (i.e., branched acyl-chains) than the acetyl-CoA-specific ecKASIII. The catalytic properties of the taKASIII and aaKASIII had not previously been experimentally determined, but we projected that because they are sourced from bacteria that produce large quantities of fatty acids with bulky chemical structures at their $\omega$-ends these enzymes may be able to utilize larger acyl-CoA substrates. Coupling the ability of the aaKASIII to utilize 3-hydroxybutyryl-CoA as a substrate with the capacity to generate this substrate in vivo proved successful in generating a strain that can produce HBFAs.

This achievement has wider implications, setting a precedent bioengineering strategy for diversifying the products that can be produced from the fatty acid biosynthesis pathway. Thus, one can modify the available acyl-CoA substrate pools for the KASIII enzyme in combination with KASIII variants that can make use of these acyl-CoAs. Specifically, this KASIII based technology can be used as a general platform for production of other $\omega$-functionalized fatty 
acids, such $\alpha, \omega$-diacids, $\omega$-amino acids, $\omega$-unsaturated acids, and $\omega$ halogenated acids that have many chemical applications, but are not readily accessible by biological or chemical synthetic routes ${ }^{36,37}$. More widely, this strategy could also be applied to diversify the natural product portfolio that can be produced by the broader class of Type III iterative polyketide synthases (PKS) that are structural homologs of KASIII enzymes ${ }^{38}$. Approaches to load alternative starter units to bacterial PKSs and combinatorial biosynthesis approaches have been described in the literature that could serve as alternative approaches to synthesize $\omega$-functionalized polyketides and natural products such as macrolactam antibiotics and $\omega$-aromatic fatty acids ${ }^{39-41}$.

The occurrence of a double bond in the alkyl-chain of our HBFA products would alter the physical-chemical properties of the HBFAs compared to the saturated HBFAs, specifically lowering the melting point of the former molecules. Moreover, the occurrence of the double bond would allow for additional chemistries to be aimed at this functional group providing a combined biological-chemical route to additional products, such as epoxides via oxidation, diacids via metathesis, and diesters via cross-metathesis ${ }^{42}$. Such chemicals would have wide ranging applications in polymers, and in the manufacture of surfactants, and cleaning agents.

A wide range of possible chemical transformations of HBFAs have been experimentally described resulting in products with enhanced functionalities ${ }^{37}$, thus demonstrating their potential to spur innovation in newer technological areas. Specifically, HBFAs are considered to be excellent monomers for 
synthesizing polyethylene-like biobased plastics ${ }^{43,44}$, or they can be readily converted to macrocyclic lactones ${ }^{45}$ that have applications in pharmaceutical industry $^{46}$ and flavors and fragrances ${ }^{47}$.

HBFAs occur naturally in glycolipids, namely sophorolipids ${ }^{48,49}$ and they impart superior functional properties as biosurfactants ${ }^{15}$. Sophorolipids are synthesized by fermentation of long-chain fatty acids and other long-chain compounds in certain yeasts, Candida bombicola ${ }^{50}$, Torulopsis magnoliae ${ }^{48}$ and Torulopsis gropengiesseri ${ }^{51}$. These microbial HBFAs appear to be produced by the hydroxylation of a fatty acid precursor by a specific cytochrome P450 monooxygenase ${ }^{43,52}$. While this yeast-based platform for producing HBFAs require long-chain fatty acids as substrates, various chemical synthesis routes have also been proposed, and these also require expensive functionalized substrates and multi-step processes ${ }^{36,53}$. The platform described herein produces HBFAs from a sugar feedstock, which may offer an alternative metabolic process than the fatty acid-dependent process available in the sophorolipid producing yeasts ${ }^{48,50,51}$. Thus although sugars are a less expensive feedstock than fatty acids, this new platform will require more optimization to compete with the yeast sophorolipid producing strains that yield a titer of up to $400 \mathrm{~g} / \mathrm{L}^{54}$.

Despite this current limitation, we did realize a nearly 1000-fold improvement in these parameters from the initial demonstration of the platform in $R$. rubrum, which offers optimism that further improvements can be achieved. The improvements to date included switching the host for expressing the 
platform to an $E$. coli strain that can be more readily manipulated via genetic strategies. Targeted genetic manipulations were guided by the principle of eliminating wasteful competing reactions. For example deleting the $\mathrm{fabH}$ gene that encodes the endogenous KASIII, and eliminating processes that can potentially catabolize the HBFAs, i.e., fatty acid $\beta$-oxidation pathway, by deleting the fadD gene.

Additional improvements in HBFA titer (by 3-fold) were achieved by optimizing the fermentation conditions, specifically optimizing the $\mathrm{C} / \mathrm{N}$ ratio, inoculum size, the post-induction temperature, induction time, and concentration of the inducer of the reconstructed HBFA pathway. The theoretical yield of a 16carbon HBFA is $37.8 \%$ based on the overall reaction: 4 Glucose $\rightarrow 8$ AcetylCoA $\rightarrow 15$-hydroxy-hexadecanoic acid. The actual yield of our process is less than $1 \%$ of the theoretical yield, and this can be possibly attributed to a number of factors including low catalytic efficiency of the aaKASIII enzyme, limited substrate availability and rate limitation by certain enzymes of the fatty acid synthesis pathway, such as acetyl CoA carboxylase. As previously demonstrated in the development of fatty acid producing strains ${ }^{55-58}$, improvements in HBFA titer and yield are possible via rational engineering of the aaKASIII enzyme to improve its catalytic efficiency, and via other standard genetic modifications of $E$. coli that increase the flux through the fatty acid biosynthetic pathway by overexpression of acyl-ACP thioesterase ${ }^{59}$, acetylCoA carboxylase $(\operatorname{acc} A B C D)^{58}$ and/or manipulation of transcription factors (e.g., FadR) ${ }^{5}$. Our initial attempts at these types of improvements with acylACP thioesterase did not yield the expected improvement, which may indicate 
that improvements in HBFA titers may require exploration of other mechanisms.

\section{MATERIALS AND METHODS}

Chemicals and reagents. Unless otherwise specified, all chemicals, biochemicals, solvents and reagents were purchased from Sigma-Aldrich (St. Louis, MO, USA). Antibiotics were purchased from Fisher Scientific (Waltham, MA).

Gene synthesis and cloning. The ORF sequences coding for aaKASIII from Alicyclobacillus acidocaldarius subsp. acidocaldarius DSM 446 (Genbank accession number - ACV57087.1); and taKASIII from Thermus aquaticus (Genbank accession number - EED09609.1) were codon-optimized for expression in E. coli, chemically synthesized (with restriction sites for Xbal and HindIII at the 5' and 3' ends respectively) and cloned into the pUC57 vector (GenScript, Piscataway, NJ, USA) to generate the plasmids, pUC_aaKASIII and pUC_taKASIII. The chemically synthesized aaKASIII and taKASIII ORFs were cloned into the pDEST-17 vector with N-terminal His tag via Gateway Cloning (Invitrogen, Carlsbad, CA) to generate plasmids, pDEST_aaKASIII and pDEST_taKASIII.

The fabH gene (Genbank accession number - AAG55837.1) that encodes $E$. coli KASIII (ecKASIII) was PCR-amplified from E. coli strain MG1655 (The E. coli Genetic Stock Center, New Haven, CT), and cloned into pDEST17 vector using Gateway cloning (Invitrogen, Carlsbad, CA), resulting in the plasmid 
pDEST_ecKASIII. The yhfB gene (Genbank accession number CAB12857.1) that encodes B. subtilis KASIIIb (bsKASIIIb) was PCR-amplified from B. subtilis strain 168 (The Bacillus Genetic Stock Center, Columbus, OH) and cloned into the pDEST17 expression vector via Gateway cloning to generate plasmid pDEST_bsKASIIlb.

Four pCA24N expression vectors that harbor the fabD, fabG, acpP and aas genes were obtained from the National BioResource Project (NIG, Japan), which encode malonyl-CoA: ACP transacylase (MCAT or FabD), $\beta$-ketoacyl ACP reductase (KAR or FabG), holo-ACP and fused 2-acylglycerophosphoethanolamine acyl transferase/acyl-acyl carrier protein synthetase, respectively. The acpP and aas genes were subsequently cloned into the pETDUET vector (Novagen, Merck KGaA, Darmstadt, Germany) to generate pETDUET_ACPP_AAS vector. Each of these constructs encodes an Nterminal His-tag.

B. subtilis strains, plasmids, DNA manipulation and growth conditions. B. subtilis was routinely grown in LB medium at $37{ }^{\circ} \mathrm{C}$. B. subtilis minimal medium was composed of Spizizen salts, supplemented with $0.5 \%$ glucose and amino acids. As needed, media were supplemented with appropriate antibiotics, erythromycin $(1 \mu \mathrm{g} / \mathrm{ml})$ or ampicillin $(100 \mu \mathrm{g} / \mathrm{ml})$. Isopropyl- $\beta$ thiogalactopyranoside (IPTG) and 5-bromo-4-chloro-3-indolyl- $\beta$ galactopyranoside (X-gal) were used at concentrations of $0.4-1 \mathrm{mM}$ and 40 $\mu \mathrm{g} / \mathrm{ml}$ respectively. As needed, media were supplemented with $10-100 \mu \mathrm{M}$ individual fatty acids, suspended in $0.01 \%(v / v)$ Brij 58P detergent. 
DNA manipulation techniques such as PCR amplification, plasmid preparation, restriction endonuclease digestion, agarose gel electrophoresis and genetic transformation were carried out by standard molecular biology methods. Transformation of $B$. subtilis was conducted on modified competent medium.

B. subtilis $\Delta y j a X \Delta y h f B$ deletion mutant strain was created by first deleting the yjaX gene, which encodes bsKASIIla, using pMU4A plasmid and then deleting the $y h f B$ gene, which encodes bsKASIllb, by using pUCB-erm. The pMU4A plasmid was derived from pMUTIN4 plasmid $^{60}$, and it contained two yjaXderived fragments, one upstream and one downstream of the yjaX open reading frame (ORF). The upstream portion (897 bp) spanned from 860-bp upstream of the yjaX ORF to 37-bp within this ORF. The downstream fragment (897 bp) spanned from 799-bp downstream to 98-bp within the 3'end of the yjaX ORF. Each fragment was initially PCR amplified from $B$. subtilis strain 168 with the primer pairs, AUf-Pacl and AUr-Sall, and ADf-Sall and ADr-Pstl (Supplementary Table 2). The resulting fragments were cloned into the integration vector pMUTIN4, at the Pacl and Pstl sites, respectively, to generate fusions with the lacZ reporter gene. The resulting pMU4A plasmid contains an in-frame 135 bp-yjaX coding fragment that is missing 804 bp from the middle of the yjaX-ORF; the fact that this deletion allele carries an in-frame ORF avoids any polar effect on the downstream genes of the yjaXcontaining transcription unit. 
The pUCB-erm plasmid was constructed by an analogous procedure as used for pMU4A, except that this vector was derived from plasmid pUC19 and the erythromycin-resistant gene (erm) was inserted between the 836-bp upstream fragment and 802-bp downstream DNA fragments of the yhfB ORF.

The single deletion mutant strain, B. subtilis $\Delta y j a X$, was generated by homologous recombination via a two-step procedure using the plasmid pMU4A. Briefly, pMU4A was transformed into the wild-type strain B. subtilis strain 168, followed by selection for erythromycin-resistance that would be conferred by a recombination crossover event between pMU4A and the $B$. subtilis genome. The recovered integrant colonies were grown in LB liquid medium without erythromycin, and the overnight cultures were diluted 1:10 ${ }^{7}$, and $100 \mu \mathrm{l}$ of the diluted culture was plated on LB medium with IPTG and Xgal. Because the pMUTIN4 plasmid harbors lacZ, one can identify those strains that have undergone a second recombination event resulting in the loss of $\beta$-galactosidase activity (encoded by the pMUTIN4 vector) and thus appearing as white colonies when grown on X-gal containing plates. Deletion mutants were confirmed via PCR amplification across the deleted portion of yjax.

The double deletion mutant strain, $\Delta y j a X \Delta y h f B:: e r m$ was generated by homologous recombination via a one-step procedure using the plasmid pUCB-erm. Briefly, the $y$ hfB-deletion plasmid, pUCB-erm was linearized via digestion with EcoRI and subsequently transformed into the mutant $\Delta y j a X$ strain. Resultant $\Delta y j a X \Delta y h f B$ double mutant colonies were selected on 
media containing erythromycin and anteiso-C16:0 fatty acid, the inclusion of the latter was to enable rescuing of the lethal double mutant. PCR confirmation of the $\Delta y j a X$ and $\Delta y h f B:: e r m$ alleles were performed using the primer pairs (Supplementary Table 2), lofAf and lofAr, and lofBf and lofBr, respectively.

Genetic complementation of the $B$. subtilis $\Delta y j a X \Delta y h f B$ double mutant strain with aaKASIII, taKASIII or ecKASIII expression vectors was conducted using pUCB-erm-derived plasmids, carrying the different KASIII ORF sequences. In these vectors each of the different KASIII ORFs were under the control of the Pspac promoter, and were inserted between the downstream and upstream DNA fragments of the 135-bp ORF in the $\Delta y h f B$ allele of the $\Delta y j a X \Delta y h f B:: e r m$ double mutant.

\section{R. rubrum strains, plasmids, DNA manipulation and growth conditions}

The aaKASIII ORF sequence was inserted into the phaC2 locus (Rru_A2413) of the $R$. rubrum genome via a two-step recombination event. The $R$. rubrum recipient strain for this experiment was the phaC triple mutant ( $\triangle$ phaC1 $\Delta$ phaC2 $\Delta$ phaC3) that lacked any PhaC activity ${ }^{26}$. First, the upstream 922-bp flanking sequence from the R. rubrum phaC2 gene was cloned upstream of the aaKASIII sequence in plasmid pJQ200SK resulting in pTC_aaKASIII, and this chimeric construct (pTC_aaKASIII) was introduced into the E. coli strain S17-1. This construct was transferred to the R. rubrum $\Delta$ phaC1 $\Delta$ phaC2 $\Delta$ phaC3 strain via transconjugation. Transconjugation was induced by coincubating overnight the $R$. rubrum phaC triple mutant with the E. coli S17-1 
strain harbouring pTC_aaKASIII on a $0.22 \mu \mathrm{m}$ filter. The bacterial mixture was subsequently cultured on minimal medium containing gentamicin (25 $\mu \mathrm{g} / \mathrm{ml}$ ) for one to two weeks. The resulting colonies carry the product of the first recombination crossover event, which integrates the plasmid pTC_aaKASIII in the $R$. rubrum $\Delta$ phaC1 $\Delta$ phaC2 $\Delta$ phaC3 strain. Following colony purification, the recovered $R$. rubrum strains were cultured in SMN rich medium for two to three days under illumination but without gentamicin selection to allow for the second-recombination event, which excises the integrated plasmid and integrates the aaKASIII gene at the phaC2 gene (Rru_A2413) locus in the $R$. rubrum $\Delta$ phaC1 $\Delta$ phaC2 $\Delta$ phaC3 strain. Products of the double-crossover events were identified via selection on supplemented malate-ammonium medium (SMN) containing $5 \%$ sucrose $^{61}$. Resultant $R$. rubrum $\triangle$ phaC1 $\triangle$ phaC2 $\triangle p h a C 3$ aaKASIII strains were confirmed via PCR amplification of aaKASIII and subsequent sequencing.

The fatty acid productivity of $R$. rubrum strains was evaluated by growing cultures in RRNCO medium (but omitting ammonium chloride, hydrogen sulfide, carbon monoxide and carbon dioxide $)^{62}$, for 5 days and the bacterial pellet was recovered for fatty acid analysis.

E. coli strains, plasmids, DNA manipulation and growth conditions. Two pha genes, phaA (3-ketothiolase, R. rubrum locus Rru_A0274) and phaB (acetoacetyl-CoA reductase, R. rubrum locus Rru_A0273) were PCR amplified from Rhodospirillum rubrum ATCC 11170 using CloneAmp HiFi PCR Premix (TaKaRa, Clontech, Mountain View, CA) and cloned into a series 
of pCDFDuet vectors (Merck Millipore, Darmstadt, Germany) using in-Fusion HD cloning system (Clontech, Mountain View, CA). The resulting plasmids were: a) pCDFDuet_phaA contained phaA at Multiple Cloning Site 1 (MCS1); b) pCDFDuet_phaB contained phaB at MCS2; c) pCDFDuet_phaA_phaB contained phaA in MCS1 and phaB in MCS2; d) and pCDFDuet_phaB_phaA contained the two genes in the reverse order, i.e. phaB in MCS1 and phaA in MCS2 (Supplementary Table 3).

The codon-optimized cDNA sequence of aaKASIII was PCR amplified from pUC57_aaKASIII plasmid using CloneAmp HiFi PCR Premix and cloned into a pETDuet vector to generate pETDuet_aaKASIII (Supplementary Table 3).

Mutant E. coli strains were derived from E. coli strain K-12 BW25113 (Supplementary Table 3). The JW1077 strain harboring the $\Delta f a b H:: k a n$ allele was obtained from the Keio collection ${ }^{63}$. The $\Delta f a b H:: k a n \Delta f a d D:: c a m$ double knockout strain (OC100) was derived from JW1077 using the one-step inactivation method of Datsenko and Wanner ${ }^{64}$.

The E. coli $\Delta f a b H:$ kan $\Delta f a d D:: c a m$ mutant was generated by starting with strains JW1077 that harbors the $\Delta f a b H:: k a n$ allele. PCR primers containing fadD gene flanking sequences (fadDH1P1cam and fadDH2P2cam (Supplementary Table 2)) were used for the amplification of a cam $^{\mathrm{R}}$ cassette from a pKD3 plasmid template (obtained from the E. coli Genetic Stock Center, CGSC\#: 7631, Yale, New Haven, CT). The $\Delta f a b H:: k a n \Delta f a d D:: c a m$ mutant cells were recovered on Tryptone Yeast Extract (TYE) agar plates 
containing kanamycin and chloramphenicol. Agarose gel electrophoresis was used to confirm the replacement of the native $\operatorname{fad} D$ gene with the $\mathrm{cam}^{\mathrm{R}}$ knockout cassette. PCR amplification of the native fadD gene was performed using gene specific primers, fadD- $U$, fadD-D and PCR amplification of the knockout cassette was conducted with the fadDH1P1cam, fadDH2P2cam primers (Supplementary Table 2).

The plasmids pCDFDuet_phaA_phAB and pETDuet_aaKASIII were transformed into E. coli $\Delta f a b H:$ kan $\Delta$ fadD::cam mutant strain (OC100) by electroporation, to generate strain OC101. Similarly, strain OC102 was obtained by transforming $E$. coli $\Delta f a b H:$ kan $\Delta f a d D:: c a m$ mutant (OC100) with pCDFDuet_phaB_phaA and pETDuet_aaKASIII plasmids. Thioesterase (TE) sourced from Cuphea seeds was overexpressed in strain OC101 using plasmid pLR 506 (i.e. pETDuet vector carrying aaKASIII at MCS1 and TE at MCS2).

During strain construction, cultures were grown at $37{ }^{\circ} \mathrm{C}$ in LB medium and appropriate antibiotics were included, kanamycin $(50 \mu \mathrm{g} / \mathrm{mL})$, ampicillin (100 $\mu \mathrm{g} / \mathrm{mL})$, spectinomycin $(100 \mu \mathrm{g} / \mathrm{ml})$ and chloramphenicol $(20 \mu \mathrm{g} / \mathrm{mL})$. Overnight cultures were inoculated into fresh LB media to OD of 0.1. After 4-6 hours of incubation at $37^{\circ} \mathrm{C}$, expression of aaKASIII was induced with $0.5 \mathrm{mM}$ IPTG. The cultures were cultivated at $22{ }^{\circ} \mathrm{C}$ at $250 \mathrm{rpm}$, and samples were collected $24 \mathrm{~h}$ or $48 \mathrm{~h}$ after induction for fatty acid analysis. All experiments were performed in triplicates. 
Fatty acid extraction. Fatty acids were extracted from cells or from the growth media using a chloroform/methanol/water extraction method. In particular, the cells or media were acidified with $1 \mathrm{M} \mathrm{HCl}$, and $4 \mathrm{ml}$ chloroformmethanol (1:1 vol/vol) was added to recover the fatty acids. After vortexing for 10 min and centrifuging at $3000 \times g$ for 4 min, the lower chloroform phase was transferred to a new tube and evaporated under a stream of nitrogen gas until the samples were concentrated to $\sim 100 \mu \mathrm{l}$. Samples were derivatized and $1 \mu \mathrm{l}$ of each derivatized sample was analyzed by GC-MS. Specifically, extracted fatty acids from $B$. subtilis strains were derivatized by converting to picolinyl esters (lipidlibrary.aocs.org/ms/ms02/index.htm) or methyl esters using methanolic- $\mathrm{HCl}$ at $80{ }^{\circ} \mathrm{C}$ for 60 minutes. Extracted fatty acids from $R$. rubrum and E.coli strains were derivatized by converting to trimethylsilyl esters.

DMDS derivatization. To determine the location of the double bonds in the fatty acid chain, we used a DMDS derivatization method ${ }^{65}$. Briefly, methylated fatty acid extracts were dissolved in hexane with DMDS iodine solution and incubated overnight at $40^{\circ} \mathrm{C}$. After the addition of $5 \%$ sodium thiosulfate, fatty acid methyl esters were recovered by hexane extraction, silylated and analyzed using GC/MS.

GC-MS analysis. GC-MS analysis of derivatized fatty acids was performed on an Agilent 6890N gas chromatograph (Agilent Technologies, Santa Clara, CA) equipped with an HP-5 MS fused-silica column (length $30 \mathrm{~m}$, internal diameter $250 \mu \mathrm{m}$, film thickness $0.25 \mu \mathrm{m}$ ), coupled to an Agilent 5973 MSD 
detector. The temperatures of the injector and MSD interface were both set to $250{ }^{\circ} \mathrm{C}$. Helium $(1.8 \mathrm{ml} / \mathrm{min})$ was used as a carrier gas. The temperature gradient was from $80-220{ }^{\circ} \mathrm{C}$ at $4{ }^{\circ} \mathrm{C} / \mathrm{min}$, then to $320^{\circ} \mathrm{C}$ at $20^{\circ} \mathrm{C} / \mathrm{min}$, and then isothermal at $320^{\circ} \mathrm{C}$ for $2 \mathrm{~min}$.

Protein expression and purification. The OverExpress ${ }^{T M}$ C41 (Lucigen, Middletown, WI) strain was used for expression of all KASIII, FabD, FabG and holo-ACP proteins, from their respective pDEST17, pCA24N and pETDuet constructs. The OverExpress ${ }^{\mathrm{TM}} \mathrm{C} 41$ transformants were grown at $37^{\circ} \mathrm{C}$ in $4 \mathrm{~L}$ LB medium, supplemented with $100 \mu \mathrm{g} / \mathrm{ml}$ ampicillin. Protein expression was induced by addition of IPTG to a final concentration of $0.4 \mathrm{mM}$, when the $\mathrm{OD}_{600}$ of the culture was between $0.6-0.8$. After $16-18 \mathrm{~h}$ of induction at $25^{\circ} \mathrm{C}$, cells were harvested by centrifugation $\left(10,000 \times g, 4^{\circ} \mathrm{C}, 10\right.$ minutes). The cell pellet was suspended in lysis buffer $(0.5 \mathrm{M} \mathrm{NaCl}, 5 \mathrm{mM}$ imidazole, $20 \mathrm{mM}$ Tris- $\mathrm{HCl}, \mathrm{pH} 8.0,0.1 \mathrm{mg} / \mathrm{ml}$ phenylmethylsulfonyl fluoride, $0.1 \%$ Triton-X 100) and subjected to sonication (10 s pulses separated by $3 \mathrm{~s}$ intervals for a total of 3 minutes). Following centrifugation $\left(10,000 \times \mathrm{g}, 4^{\circ} \mathrm{C}, 30\right.$ minutes $)$, the supernatant containing the soluble protein fraction was recovered and filtered through a $0.45 \mu$ filter (Corning, the Netherlands). The recombinant Histagged proteins were purified using PerfectPro Ni-NTA His-bind resin (5 Prime $\mathrm{GmbH}$, Gaithersburg, MD). The soluble protein extract was applied to $4 \mathrm{ml}$ packed column of the resin, and after washing the unbound proteins with wash buffers $(0.5 \mathrm{M} \mathrm{NaCl}, 20 \mathrm{mM}$ Tris- $\mathrm{HCl}, \mathrm{pH}$ 8.0) supplemented with 20 $\mathrm{mM}$ and $40 \mathrm{mM}$ imidazole, the His-tagged proteins of interest were eluted from the column with the wash buffer containing $250 \mathrm{mM}$ imidazole. The 
purified His-tagged proteins were dialyzed against $0.1 \mathrm{M}$ sodium phosphate buffer, $\mathrm{pH} 7.2$, at $4{ }^{\circ} \mathrm{C}$ and concentrated using Amicon ultrafiltration centrifugal devices with 10,000 MWCO (Millipore, Billerica, MA). Protein purity was assessed by Coomassie-stained SDS-PAGE, which showed presence of near-homogenous protein preparations (greater than 98\% purity). Protein concentrations were determined by Bradford's assay (BioRad, Hercules, CA). The concentrated proteins were either stored at $-80^{\circ} \mathrm{C}$ or immediately used for enzyme activity assays and thermal shift assays.

KASIII activity assay. KASIII enzymatic activity was ascertained via spectrophotometric assay, which coupled the appearance of 3-ketoacyl-ACP to the oxidation of $\mathrm{NADPH}$, using the E. coli FabG protein to reduce 3ketoacyl-ACP to 3-hydroxyacyl-ACP. The assay was performed in 96-well plate-format with three technical replicates for each reaction condition. In a total volume of $100 \mu \mathrm{l}$ for each reaction, the reaction mix containing $400 \mu \mathrm{M}$ holo-ACP, $400 \mu \mathrm{M}$ malonyl-CoA, 10 mM DTT, 10-400 $\mu \mathrm{M}$ acyl-CoA substrate and $400 \mu \mathrm{M}$ NADPH in $0.1 \mathrm{M}$ sodium phosphate buffer $(\mathrm{pH} 7.2)$. This mixture was pre-incubated with $60 \mu \mathrm{g}$ of FabD for two minutes to initiate synthesis of malonyl-ACP from malonyl-CoA and holo-ACP. The KASIII reaction was then started by the addition of $30 \mu \mathrm{g}$ of FabG and varying concentrations of KASIII enzyme $(0.5-15 \mu \mathrm{g})$. As KASIII catalysed the condensation acyl-CoA with malonyl-ACP to form 3-ketoacyl-ACP, FabG reduced this 3-ketoacyl-ACP intermediate to 3-hydroxyacyl ACP in presence of NADPH. Change in absorbance at $340 \mathrm{~nm}$ due to the conversion of NADPH to NADP+, catalysed by FabG, was recorded using Synergy 2 Multi-Mode Microplate Reader 
(BioTek, Winooskit, VT). This assay was used to assess the ability of different KASIII enzymes to use different acyl-CoA substrates (i.e., acetyl-CoA, isobutyryl-CoA and 3-hydroxybutyryl-CoA). Specific activity was calculated by varying the amount of KASIII and ascertaining the moles of product (NADP ${ }^{+}$) formed per unit time per mg of KASIII. Km was calculated by varying the concentration of acyl-CoA substrate from $10 \mu \mathrm{M}$ to $400 \mu \mathrm{M}$, while keeping the KASIII concentration constant.

Circular Dichroism (CD) spectroscopy. All CD spectra of purified KASIII proteins $(0.1-0.25 \mathrm{mg} / \mathrm{ml}$ in $10 \mathrm{mM}$ sodium phosphate buffer, $\mathrm{pH}$ 7.2) were collected using a Jasco J-710 Spectropolarimeter, in a $0.1 \mathrm{~cm}$ cell at $25^{\circ} \mathrm{C}$. Far-UV spectra were recorded with a bandwidth of $1.0 \mathrm{~nm}$ and a time response of $8 \mathrm{~s}$ with a total of two accumulations of data.

Thermal shift binding assays. Thermal shift assays were performed with a Light Cycler 480 System (Roche Applied System) using $20 \mu$ reactions in a 96-well plate format ${ }^{22}$. KASIII protein $(2 \mu \mathrm{M}-20 \mu \mathrm{M})$ was mixed with SYPRO Orange dye (Sigma-Aldrich, St. Louis, MO) $(5 X-10 X$ molar excess of protein concentration) in $0.1 \mathrm{M}$ sodium phosphate buffer, $\mathrm{pH}$ 7.2. For each assay, an acyl-CoA ligand (coenzyme-A, acetyl-CoA, propionyl-CoA, butyryl-CoA, hexanoyl-CoA, isobutyryl-CoA, isovaleryl-CoA, 3-hydroxybutyryl-CoA, malonyl-CoA, methylmalonyl-CoA, crotonyl-CoA, benzoyl-CoA or phenylacetyl-CoA) was added in 50-fold molar excess of the KASIII protein being tested. For negative controls, water was used instead of an acyl-CoA ligand. Plates were sealed with an optical sealing tape, and then heated in the 
Light Cycler 480 instrument from $20^{\circ} \mathrm{C}$ to $95^{\circ} \mathrm{C}$ at the rate of $1{ }^{\circ} \mathrm{C} /$ minutes. Melting temperatures of the proteins were calculated using the Light Cycler 480 Protein Melt program (Roche Applied Science, Penzberg, Germany), and the effect of different ligands on the melting temperatures of each KASIII were determined. Data from quadruplicate experiments were collected for each protein.

Strain cultivation for fermentation conditions optimization. The bioengineered E. coli strain OC101 strain was cultured on LB-agar plates supplemented with streptomycin $(50 \mu \mathrm{g} / \mathrm{ml})$, ampicillin $(100 \mu \mathrm{g} / \mathrm{ml})$ and kanamycin $(50 \mu \mathrm{g} / \mathrm{ml})$ and maintained at $37^{\circ} \mathrm{C}$. A single colony of the $E$. coli strain was inoculated into $3 \mathrm{~mL}$ LB liquid medium supplemented with antibiotics and cultured for $12-16 \mathrm{hrs}$ at $37{ }^{\circ} \mathrm{C}$. The inoculum was added aseptically to a $125 \mathrm{ml}$ shake flask containing $25 \mathrm{ml}$ M9 minimal medium supplemented with the antibiotics. M9 medium containing $20 \mathrm{~g} / \mathrm{L}$ glucose as carbon source and $\mathrm{NH}_{4} \mathrm{Cl}$ as nitrogen source as well as $0.5 \mathrm{~g} / \mathrm{L} \mathrm{NaCl}$, $\mathrm{Na}_{2} \mathrm{HPO}_{4} \cdot 7 \mathrm{H}_{2} \mathrm{O} 12.8 \mathrm{~g} / \mathrm{L}, \mathrm{KH}_{2} \mathrm{PO}_{4} 3 \mathrm{~g} / \mathrm{L}, \mathrm{MgSO}_{4} 0.24 \mathrm{~g} / \mathrm{L}, \mathrm{CaCl}_{2} 0.002 \mathrm{~g} / \mathrm{L}$, $\mathrm{FeSO}_{4} 0.003 \mathrm{~g} / \mathrm{L}, 0.005 \mathrm{~g} / \mathrm{L}$ thiamine $\mathrm{HCl}$ and $10 \mathrm{ml} / \mathrm{L}$ BME vitamins. The culture was cultivated at $37{ }^{\circ} \mathrm{C}$ and $250 \mathrm{rpm}$, and gene expression was induced by the addition of IPTG, the concentration of which varied depending on the experiment. During the cultivation, the optical density of the culture was monitored and cells were harvested for fatty acid analysis when stationary phase was reached. 


\section{ACKNOWLEDGEMENTS}

This work was partially supported by the U.S. National Science Foundation (Award No. EEC-0813570) through its Engineering Research Center Program, which supports the Center for Biorenewable Chemicals (CBiRC), headquartered at lowa State University and including Rice University, the University of California-Irvine, the University of New Mexico, the University of Virginia, and the University of Wisconsin-Madison. This work was also supported by an NSF STTR Phase I award to OmegaChea Biorenewables LLC (IIP-1321520), and awards from the i6 Green and lowa Regents Innovation Funds, administered by lowa State University Research Foundation, Inc. (ISURF). Shivani Garg, Marna D. Yandeau-Nelson and Basil J. Nikolau have equity interests in OmegaChea Biorenewables LLC and serve as the Board Members of the company. Ludmila Rizhsky is an employee of OmegaChea Biorenewables LLC. The terms of this arrangement have been reviewed and approved by lowa State University in accordance with its conflict of interest policies. We would like to thank lowa State University undergraduate students, Ms. Morgan Becker and Mr. Ruben Garcia, for their assistance in protein expression and purification. We would also like to thank

Dr. Ann Perera of W.M. Keck Metabolomics Research Laboratory for technical assistance in conducting enzyme assays and GC-MS analysis. We also want to thank Dr. Charles Stewart (The Salk Institute for Biological Studies, La Jolla) for his guidance on the use of thermal shift binding assays. 


\section{REFERENCES}

1. Nikolau, B.J., Perera, M.A., Brachova, L. \& Shanks, B. Platform biochemicals for a biorenewable chemical industry. Plant J 54, 536-545 (2008).

2. Steen, E.J. et al. Microbial production of fatty-acid-derived fuels and chemicals from plant biomass. Nature 463, 559-562 (2010).

3. Handke, P., Lynch, S.A. \& Gill, R.T. Application and engineering of fatty acid biosynthesis in Escherichia coli for advanced fuels and chemicals. Metab Eng 13, 28-37 (2011).

4. Metzger, J.O. \& Bornscheuer, U. Lipids as renewable resources: current state of chemical and biotechnological conversion and diversification. Appl Microbiol Biotechnol 71, 13-22 (2006).

5. Janßen, H.J. \& Steinbüchel, A. Fatty acid synthesis in Escherichia coli and its applications towards the production of fatty acid based biofuels. Biotechnol Biofuels 7, 7 (2014).

6. Rock, C.O. \& Cronan, J.E. Escherichia coli as a model for the regulation of dissociable (type II) fatty acid biosynthesis. Biochim Biophys Acta 1302, 1-16 (1996).

7. Stewart, C., Vickery, C.R., Burkart, M.D. \& Noel, J.P. Confluence of structural and chemical biology: plant polyketide synthases as biocatalysts for a biobased future. Curr Opin Plant Biol 16, 365-372 (2013).

8. Austin, M.B. \& Noel, J.P. The chalcone synthase superfamily of type III polyketide synthases. Nat Prod Rep 20, 79-110 (2003).

9. Metz, J.G. et al. Production of polyunsaturated fatty acids by polyketide synthases in both prokaryotes and eukaryotes. Science 293, 290-293 (2001).

10. Ben-Israel, I. et al. Multiple biochemical and morphological factors underlie the production of methylketones in tomato trichomes. Plant Physiol 151, 1952-1964 (2009).

11. Lai, C.Y. \& Cronan, J.E. Beta-ketoacyl-acyl carrier protein synthase III (FabH) is essential for bacterial fatty acid synthesis. J Biol Chem 278, 51494-51503 (2003).

12. Choi, K.H., Heath, R.J. \& Rock, C.O. beta-ketoacyl-acyl carrier protein synthase III $(\mathrm{FabH})$ is a determining factor in branched-chain fatty acid biosynthesis. J Bacteriol 182, 365-370 (2000).

13. Gajiwala, K.S. et al. Crystal structures of bacterial FabH suggest a molecular basis for the substrate specificity of the enzyme. FEBS Lett 583, 2939-2946 (2009).

14. Heath, R.J. \& Rock, C.O. The Claisen condensation in biology. Nat Prod Rep 19, 581-596 (2002).

15. Ashby, R.D., Solaiman, D.K. \& Foglia, T.A. Property control of sophorolipids: influence of fatty acid substrate and blending. Biotechnol Lett 30, 1093-1100 (2008).

16. Cantu, D.C., Chen, Y., Lemons, M.L. \& Reilly, P.J. ThYme: a database for thioester-active enzymes. Nucleic Acids Res 39, D342-346 (2011).

17. Chen, Y. et al. Structural classification and properties of ketoacyl synthases. Protein Sci 20, 1659-1667 (2011).

18. Jackson, T.J., Ramaley, R.F. \& Meinschein, W.G. Fatty acids of a nonpigmented, thermophilic bacterium similar to Thermus aquaticus. Arch Mikrobiol 88, 127-133 (1973).

19. Moore, B.S., Poralla, K. \& Floss, H.G. Biosynthesis of the Cyclohexanecarboxylic Acid Starter Unit of $\omega$-Cyclohexyl Fatty Acids in Alicyclobacillus acidocaldarius Journal of the American Chemical Society 115, 5267-5274 (1993). 
20. Heath, R.J. \& Rock, C.O. Inhibition of beta-ketoacyl-acyl carrier protein synthase III (FabH) by acyl-acyl carrier protein in Escherichia coli. J Biol Chem 271, 10996-11000 (1996).

21. Kaneda, T. Iso- and anteiso-fatty acids in bacteria: biosynthesis, function, and taxonomic significance. Microbiol Rev 55, 288-302 (1991).

22. Niesen, F.H., Berglund, H. \& Vedadi, M. The use of differential scanning fluorimetry to detect ligand interactions that promote protein stability. Nat Protoc 2, 2212-2221 (2007).

23. Ericsson, U.B., Hallberg, B.M., Detitta, G.T., Dekker, N. \& Nordlund, P. Thermofluor-based high-throughput stability optimization of proteins for structural studies. Anal Biochem 357, 289-298 (2006).

24. Vedadi, M. et al. Chemical screening methods to identify ligands that promote protein stability, protein crystallization, and structure determination. Proc Natl Acad Sci U S A 103, 15835-15840 (2006).

25. Brandl, H., Knee, E.J., Fuller, R.C., Gross, R.A. \& Lenz, R.W. Ability of the phototrophic bacterium Rhodospirillum rubrum to produce various poly (betahydroxyalkanoates): potential sources for biodegradable polyesters. Int J Biol Macromol 11, 49-55 (1989).

26. Jin, H. \& Nikolau, B.J. Role of genetic redundancy in polyhydroxyalkanoate (PHA) polymerases in PHA biosynthesis in Rhodospirillum rubrum. $J$ Bacteriol 194, 5522-5529 (2012).

27. Jing, F. et al. Phylogenetic and experimental characterization of an acyl-ACP thioesterase family reveals significant diversity in enzymatic specificity and activity. BMC Biochem 12, 44 (2011).

28. Singhasuwan, S., Choorit, W., Sirisansaneeyakul, S., Kokkaew, N. \& Chisti, $\mathrm{Y}$. Carbon-to-nitrogen ratio affects the biomass composition and the fatty acid profile of heterotrophically grown Chlorella sp. TISTR 8990 for biodiesel production. J Biotechnol (2015).

29. Braunwald, $\mathrm{T}$. et al. Effect of different $\mathrm{C} / \mathrm{N}$ ratios on carotenoid and lipid production by Rhodotorula glutinis. Appl Microbiol Biotechnol 97, 6581-6588 (2013).

30. Chen, C., Yeh, K., Chang, H. \& Chang, J. Strategies to Improve Oil/Lipid Production of Microalgae in Outdoor Cultivation Using Vertical Tubular-type Photobioreactors. Energy Procedia 61, 2755-2758 (2014).

31. Lu, S. et al. Metabolic profiling reveals growth related FAME productivity and quality of Chlorella sorokiniana with different inoculum sizes. Biotechnology and Bioengineering 109, 1651-1662 (2012).

32. Donovan, R., Robinson, C. \& Glick, B. Review: Optimizing inducer and culture conditions for expression of foreign proteins under the control of the lac promoter. Journal of Industrial Microbiology 16, 145-154 (1996).

33. Larentis, A.L. et al. Evaluation of pre-induction temperature, cell growth at induction and IPTG concentration on the expression of a leptospiral protein in E. coli using shaking flasks and microbioreactor. BMC Res Notes 7, 671 (2014).

34. Klein, K., Steinberg, R., Fiethen, B. \& Overath, P. Fatty acid degradation in Escherichia coli. An inducible system for the uptake of fatty acids and further characterization of old mutants. Eur J Biochem 19, 442-450 (1971).

35. Overath, P., Pauli, G. \& Schairer, H.U. Fatty acid degradation in Escherichia coli. An inducible acyl-CoA synthetase, the mapping of old-mutations, and the isolation of regulatory mutants. Eur J Biochem 7, 559-574 (1969).

36. Metzger, J.O. Fats and oils as renewable feedstock for chemistry. European Journal of Lipid Science and Technology 111, 865-876 (2009). 
37. Zerkowski, J.A. \& Solaiman, D.K.Y. Omega-functionalized fatty acids, alcohols, and ethers via olefin metathesis. Journal of American Oil Chemists Society 89, 1325-1332 (2012).

38. McDaniel, R., Ebert-Khosla, S., Hopwood, D.A. \& Khosla, C. Rational design of aromatic polyketide natural products by recombinant assembly of enzymatic subunits. Nature 375, 549-554 (1995).

39. Moore, B.S. \& Hertweck, C. Biosynthesis and attachment of novel bacterial polyketide synthase starter units. Nat Prod Rep 19, 70-99 (2002).

40. Cane, D.E., Walsh, C.T. \& Khosla, C. Harnessing the biosynthetic code: combinations, permutations, and mutations. Science 282, 63-68 (1998).

41. Meier, J.L. \& Burkart, M.D. The chemical biology of modular biosynthetic enzymes. Chem Soc Rev 38, 2012-2045 (2009).

42. Biermann, U., Bornscheuer, U., Meier, M.A.R., Metzger, J.O. \& Schafer, H.J. Oils and fats as renewable raw materials in chemistry. Angewandte Chemie International Edition 50, 3854-3871 (2011).

43. Lu, W. et al. Biosynthesis of monomers for plastics from renewable oils. J Am Chem Soc 132, 15451-15455 (2010).

44. Ceccorulli, G., Scandola, M., Kumar, A., Kalra, B. \& Gross, R.A. Cocrystallization of random copolymers of omega-pentadecalactone and epsilon-caprolactone synthesized by lipase catalysis. Biomacromolecules $\mathbf{6}$, 902-907 (2005).

45. Antczak, U., Gora, J., Antczak, T. \& Galas, E. Enzymatic lactonization of 15hydroxypentadecanoic and 16-hydroxyhexadecanoic acids to macrocyclic lactones. Enzyme and Microbial Technology 13, 589-593 (1991).

46. Ōmura, S. Macrolide Antibiotics: Chemistry, Biology, and Practice, Edn. Second. (Academic Press, 2002).

47. Vandamme, E.J. \& Soetaert, W. Bioflavours and fragrances via fermentation and biocatalysis. Journal of Chemical Technology and Biotechnology 77, 1323-1332 (2002).

48. Gorin, P.A.J., Spencer, J.F.T. \& Tulloch, A.P. Hydroxy fatty acid glycosides of sophorose from Torulopsis magnoliae. Canadiam Journal of Chemistry 39, 846-855 (1961).

49. Asmer, H.-J., Lang, S., Wagner, F. \& Wray, V. Microbial production, structure elucidation and bioconversion of sophorose lipids. Journal of the American Oil Chemists' Society 65, 1460-1466 (1988).

50. Daniel, H.-J., Reuss, M. \& Syldatk, C. Production of sophorolipids in high concentration from deproteinized whey and rapeseed oil in a two stage fed batch process using Candida bombicola ATCC 22214 and Cryptococcus curvatus ATCC 20509. Biotechnology Letters 20, 1153-1156 (1998).

51. Jones, D.F. \& Howe, R. Microbiological oxidation of long-chain aliphatic compounds. I. Alkanes and alk-1-enes. J Chem Soc Perkin 1 22, 2801-2808 (1968).

52. Höfer, R. et al. The Arabidopsis cytochrome P450 CYP86A1 encodes a fatty acid omega-hydroxylase involved in suberin monomer biosynthesis. $J$ Exp Bot 59, 2347-2360 (2008).

53. Villemin, D., Cadiot, P. \& Kuetegan, M. A New Synthesis of $\omega$ Hydroxyalkanoic Acids via Copper Catalysis. Synthesis 03, 230-231 (1984).

54. Pekin, G., Vardar-Sukan, F. \& Kosaric, N. Production of Sophorolipids from Candida bombicola ATCC 22214 Using Turkish Corn Oil and Honey. Engineering in Life Sciences 5, 357-362 (2005).

55. Lu, X., Vora, H. \& Khosla, C. Overproduction of free fatty acids in E. coli: implications for biodiesel production. Metab Eng 10, 333-339 (2008).

56. Clomburg, J.M. \& Gonzalez, R. Biofuel production in Escherichia coli: the role of metabolic engineering and synthetic biology. Appl Microbiol Biotechnol 86, 419-434 (2010). 
57. Liu, T., Vora, H. \& Khosla, C. Quantitative analysis and engineering of fatty acid biosynthesis in E. coli. Metab Eng 12, 378-386 (2010).

58. Davis, M.S., Solbiati, J. \& Cronan, J.E. Overproduction of acetyl-CoA carboxylase activity increases the rate of fatty acid biosynthesis in Escherichia coli. J Biol Chem 275, 28593-28598 (2000).

59. Jiang, P. \& Cronan, J.E. Inhibition of fatty acid synthesis in Escherichia coli in the absence of phospholipid synthesis and release of inhibition by thioesterase action. J Bacteriol 176, 2814-2821 (1994).

60. Vagner, V., Dervyn, E. \& Ehrlich, S.D. A vector for systematic gene inactivation in Bacillus subtilis. Microbiology 144 ( Pt 11), 3097-3104 (1998).

61. Kerby, R.L. et al. Genetic and physiological characterization of the Rhodospirillum rubrum carbon monoxide dehydrogenase system. J Bacteriol 174, 5284-5294 (1992).

62. Kerby, R.L., Ludden, P.W. \& Roberts, G.P. Carbon monoxide-dependent growth of Rhodospirillum rubrum. J Bacteriol 177, 2241-2244 (1995).

63. Baba, T. et al. Construction of Escherichia coli K-12 in-frame, single-gene knockout mutants: the Keio collection. Mol Syst Biol 2, 2006.0008 (2006).

64. Datsenko, K.A. \& Wanner, B.L. One-step inactivation of chromosomal genes in Escherichia coli K-12 using PCR products. Proc Natl Acad Sci U S A 97, 6640-6645 (2000).

65. Carlson, D., Roan, C., Yost, R. \& Hector, J. Dimethyl disulfide derivatives of long-chan alkenes, alkadienes, and alkatrienes for gas-chromatography mass-spectrometry. Analytical Chemistry 61, 1564-1571 (1989). 